Estudios Constitucionales, Año 8, No 2, 2010, pp. 633 - 674.

ISSN 0718-0195

Centro de Estudios Constitucionales de Chile Universidad de Talca

"Informe en derecho presentado ante el Tribunal Constitucional en el proceso de inconstitucionalidad del artículo 38 ter de la Ley $\mathrm{N}^{\circ} 18.933$ ” Pablo Contreras V., Gonzalo García P., Tomás Jordán D., Álvaro Villanueva R.

\title{
INFORME EN DERECHO PRESENTADO ANTE EL TRIBUNAL CONSTITUCIONAL EN EL PROCESO DE INCONSTITUCIONALIDAD DEL ARTÍCULO 38 TER DE LA LEY N 18.933
}

\author{
Pablo Contreras V., Gonzalo García P., \\ Tomás Jordán D., Álvaro Villanueva R.*
}

RESUMEN: El informe afirma la inconstitucionalidad del artículo 38 ter de la Ley No 18.933 en base a tres principales argumentos. En primer lugar, vulneraría el principio y garantía de reserva legal de los derechos fundamentales, puesto que hace recaer la regulación de los precios de los planes de las ISAPRES en las instrucciones generales dictadas por la Superintendencia de ISAPRES. En segundo lugar, la tabla de factores de riesgos, consagrada en dicho articulo, vulnera el principio de igualdad al establecer una diferenciación no justificada en razón de las condiciones de sexo y edad. Finalmente, afecta la libertad del cotizante de elegir el sistema de salud, puesto que la ISAPRE, al fijar los precios, podría marginar a los usuarios del sistema privado de salud, sin que éstos puedan optar efectivamente.

ABSTRACT: The report states the unconstitutionality of article 38 ter of Law $N^{\circ} 18.933$ based on three main arguments. First, it would violate the legal reserve warrantee and principle of the fundamental rights; hence it makes the regulation of the ISAPRES plan's prices fall under the general guidelines passed by the Superintendence of ISAPRES. Secondly, the risks factor table-established in said article-violates the principle of equality by setting an unjustified differentiation conditional to sex and age. Finally, it affects the freedom of the subscriber to really choose the health system, since the ISAPRE could marginalize the users of the system when fixing prices, hence restricting the real freedom of the choosing.

PALABRAS ClaVE: Derecho de protección a la salud. Reserva legal de derechos. Principio de igualdad. Tabla de factores de riesgo. ISAPRES.

\footnotetext{
* Pablo Contreras V. Licenciado en Ciencias Jurídicas y Sociales, Universidad Alberto Hurtado, Abogado, Magíster en Gobierno y Sociedad, Universidad Alberto Hurtado [a la fecha de presentar el informe, el autor era candidato al Magíster en cuestión]. Profesor de Derecho Constitucional, Universidad Alberto Hurtado y Adolfo Ibáńez. Gonzalo García Pino, Abogado y Magíster en Derecho Público, Pontificia Universidad Católica de Chile, Doctor en Derechos Fundamentales, Universidad Carlos III de Madrid. Profesor de Derecho Constitucional, Universidad Alberto Hurtado y Adolfo Ibáñez. Tomás Jordán D. Abogado y Magíster en Ciencia Política de la Universidad de Chile; Diploma en Estudios Especializados, Diploma en Estudios Avanzados y Magíster en Derecho Público, mención Derecho Constitucional, por la Universidad Autónoma de Barcelona. Profesor de Derecho Constitucional, Universidad Alberto Hurtado. Álvaro Villanueva R. Abogado P. U. Católica de Chile, Doctor (c) Derechos Fundamentales U. Carlos III de Madrid. Profesor de Derecho Constitucional, Universidad Alberto Hurtado; del Magíster de Gobierno y Sociedad, U. Alberto Hurtado; y del Magíster de Planificación y Gestión en Políticas Públicas, U. Central.
} 
KEY WORDS: Right to health care. Legal reserve of rights. Equality principle. Risk factors table. ISAPRES.

\section{INTRODUCCIÓN}

El presente informe en Derecho fue presentado por los autores con fecha 20 de mayo de 2010, ante el Excmo. Tribunal Constitucional, en el proceso incoado de oficio para analizar la inconstitucionalidad del artículo 38 ter de la Ley No 18.933, en virtud de lo dispuesto en el artículo 93, número $7^{\circ}$ de la Constitución Política de la República.

Por motivos editoriales, el informe ha sido modificado respecto del sistema de citas y bibliografía y ha sido reducido en lo que se refiere a los argumentos jurídicos de las ISAPRES y los fundamentos de inaplicabilidad por inconstitucionalidad que antecedieron a este proceso.

En consecuencia, el informe se estructura de la siguiente forma. En primer lugar, desarrolla aspectos relacionados con el alcance de la competencia del Excmo. Tribunal Constitucional para efectos del control de constitucionalidad abstracto y los posibles alcances fácticos o metajurídicos de una resolución jurisdiccional. En segundo lugar, el informe analiza el problema de déficit de reserva legal del artículo 38 ter en cuestión, puesto que es la regulación administrativa de la Superintendencia de ISAPRES -a través de sus Instrucciones Generales- donde se norma la forma de fijar los precios de los planes de salud. En tercer término, se analiza la afectación del principio constitucional de igualdad al aplicar los factores de sexo y edad para determinar el precio de los planes y sus alzas. Finalmente, se establece que existe una vulneración del derecho de acceso a la salud y de la libre elección del sistema de salud, toda vez que el artículo 38 ter cuestionado faculta a las ISAPRES para fijar precios de forma discriminatoria, provocando la salida de usuarios del sistema privado de salud al ámbito público.

\section{Sobre La Diferente naturaleza del JUicio}

DE CONSTITUCIONALIDAD RESPECTO DEL EXAMEN DE INAPLICABILIDAD

La secuencia de casos presentados al Excmo. Tribunal Constitucional sobre la materia de autos, lleva a la existencia de un predominio del caso concreto y del examen de los bienes jurídicos en juego, para los casos en que ha debido pronunciarse sobre la inaplicabilidad de la norma jurídica cuestionada.

Por el contrario, en un juicio de inconstitucionalidad, como el de autos, máxime si es promovido de oficio por el propio Tribunal, necesariamente debe consistir en el análisis abstracto de la inconciliabilidad de una norma con el orden constitucional vigente. En efecto, la doctrina contemporánea coincide en 
señalar que "[p]or control abstracto hay que entender aquel control cuyo único objeto es comprobar si la ley es constitucional o no haciendo abstracción de la

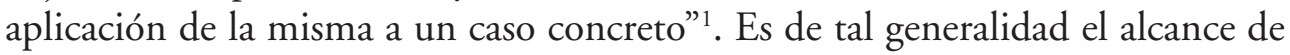
la sentencia del Excmo. Tribunal Constitucional en este tipo de causas que "[...] deroga formalmente el precepto que declara anticonstitucional” dejando "[...] de formar parte del ordenamiento jurídico". En dicho sentido "[...] se dice que el Tribunal Constitucional es legislador negativo [...]"2, no pudiendo dictar la ley, facultad reservada a los órganos colegisladores, pero sí se le permite derogarla.

Con motivos de los procesos de inaplicabilidad de la norma cuya constitucionalidad se cuestiona, las ISAPRES, de forma reiterada y sistemática, efectuaron presentaciones ante el Excmo. Tribunal Constitucional basadas en análisis abstractos, en lo relativo a su propio régimen de funcionamiento. En dichas causas, las ISAPRES en caso alguno enfrentaron argumentativamente el juicio de inaplicabilidad asociado al caso concreto de que se trataba, desconociendo el carácter propio de "control concreto" que comprende la inaplicabilidad de normas por ser contrarias a la Carta Fundamental y de cuya validez depende el respectivo fallo.

Por ello, es permitido tomar por válidas dichas argumentaciones, toda vez que el juicio de inconstitucionalidad permite un análisis de esa naturaleza.

Por el contrario, los fallos del Excmo. Tribunal Constitucional y su iter decisorio han sido argumentados de una forma diferente, con el fin de adecuarse a la naturaleza propia del juicio, sin que ello se haya alterado de manera sustancial la doctrina de tales sentencias, así como la argumentación de los demandantes.

Finalmente, debe tenerse presente lo que el constituyente originario señaló sobre estas materias, paradojalmente citando como ejemplo las materias referidas a seguridad social. En efecto, en el seno de la Comisión de Estudios de la Nueva Constitución el comisionado señor Guzmán manifestó “[...] dudas en cuanto a la procedencia de establecer en el texto fundamental la integración que la legislación en materia de seguridad social debe tener con la economía del país, porque, si bien se trata de un principio de buen sentido indiscutible, es impropio de un texto constitucional y no se divisa qué efecto jurídico podría derivarse de su consagración. Advierte que por esa vía sería factible entender que se está abriendo la facultad de recurrir de inconstitucionalidad o de inaplicabilidad, según el caso,

${ }^{1}$ Pérez Royo, Javier (2003): Curso de Derecho Constitucional (Marcial Pons, Madrid, 2003), p. 165.

2 Pérez Royo (2003), p. 165. 
respecto de una ley sobre seguridad social por estimarse que no armoniza con la legislación económica o con la política económica en práctica, lo que, a su juicio, desnaturalizaría completamente las funciones de los órganos jurisdiccionales"3. En otras palabras, no es propio del Tribunal Constitucional considerar variables de tipo económicas para efectos de determinar la constitucionalidad o inconstitucionalidad de una norma, por cuanto, lo que les propio y natural es el efectuar análisis jurídicos que dispongan sólo si la disposición legal cuestionada se adecua o no a la Carta Fundamental. Pretender que este órgano de control debiese tomar en consideración variables o condicionantes extrajurídicas simplemente sería vulnerar lo estatuido en el artículo 7o de la Constitución Política.

En consecuencia, y considerando lo dispuesto en el artículo $7^{\circ}$ de la Constitución Política, en orden a que los órganos del Estado sólo pueden realizar aquello que expresamente les faculta el ordenamiento jurídico; la eventual declaración de inconstitucionalidad del artículo 38 ter de la ley citada debe realizarse en abstracto, considerando única y exclusivamente si éste se adecua o no a la Carta Fundamental, sin tomar en consideración circunstancias de facto tales como las eventuales consecuencias económicas que generaría su declaración de inconstitucionalidad.

\section{De LAS CUESTIONES PREVIAS}

Existe un conjunto de argumentos que rodean el caso y que no necesariamente tienen fundamento jurídico y que, sin embargo, pueden ser determinantes en la resolución de la constitucionalidad de la norma cuestionada.

A dichos asuntos les hemos denominado cuestiones previas, toda vez que se refieren a si el Excmo. Tribunal Constitucional debe examinar, estar atento, medir o evaluar las consecuencias políticas, sociales y legislativas del fallo.

Además, existen otros elementos adicionales que se enmarcan dentro de la reflexión jurídica previa y que tienen una directa relación con las consecuencias.

Por un lado, está el dilema de si el Tribunal con su declaración de inconstitucionalidad crea o no una laguna jurídica en el sistema de ISAPRES; y, por otro lado, si una declaración de constitucionalidad abre o no un nuevo dilema que es la autorización por el Excmo. Tribunal Constitucional de la renuncia voluntaria de derechos fundamentales mediante cláusulas contractuales.

${ }^{3}$ Comisión de estudio de la nueva Constitución Política de la República (1978): Actas Oficiales (Sesión $403^{a}, 18$ de julio de 1978). 


\subsection{LAS CONSECUENCIAS EXTRAJURÍDICAS DEL FALLO}

\subsubsection{La presión como marketing del terror}

Hemos sido testigos todos estos días - a raíz de este caso- de un verdadero bombardeo informativo acerca de las consecuencias de este fallo. Ello constituye una pretensión desmedida por parte de quienes impugnan sucesivos fallos de mayoría en acciones de inaplicabilidad previas. La argumentación relativa a las consecuencias políticas y sociales no se ha detenido. Muchas de ellas recuerdan campañas articuladas con el objeto de señalar que la derogación de la Tabla de Factores de Riesgo de las ISAPRES lleva aparejada una solución y un descalabro. La solución serían las tarifas planas que deberían soportar todos los afiliados. El descalabro sería el pago injusto y superlativo que muchos niños, jóvenes y adultos jóvenes varones deberían efectuar como "subsidio" para permitir la presencia dentro de las ISAPRES tanto de mujeres adultas jóvenes como de mujeres y hombres de la tercera edad. Por ende, los primeros pagarían más de lo que en justicia costarían sus planes de salud. En otras palabras, ellos pagarían las consecuencias de este fallo de alcance general.

En este sentido, la presión hacia los magistrados del Excmo. Tribunal Constitucional es indudable y no nos imaginamos lo que supondrá esa dimensión en el plano personal. Sin embargo, esta presión no hace Derecho. La invocación de una argumentación no hace más que manifestar quién es más fuerte y quién puede pagar por ese tipo de defensa. Esto, por lo demás, no es una novedad en la historia constitucional de los fallos que deben emitir los jueces.

\subsubsection{Las consecuencias politicas en casos dificiles}

Cabe primeramente traer a colación de modo ilustrativo un caso de discriminación. Se trata de todo lo que rodeó al caso Brown v. Board of Education en los Estados Unidos de América. Alguien podrá sentir herida la susceptibilidad de hacer una asociación entre el predominio racial blanco manifestado en la segregación educativa y su equiparación con las ISAPRES. Nuestro interés está muy lejos de hacer esa burda asociación. De hecho, los firmantes somos casi todos usuarios de ISAPRES y nadie ha propiciado su desaparición ni menos la demonización del sistema privado de salud. Nuestra argumentación tiene por base el hecho de que estas instituciones pueden administrar de otra manera este conflicto sin hacer discriminaciones. Volvemos al ejemplo. La asociación sí puede hacerse entre la parte débil del eslabón: los negros como las mujeres de mayor edad. En este caso la fórmula lleva a la misma solución: a la discriminación con resultados segregatorios. No obstante, las diferencias entre un caso y otro 
son abismantes. Es evidente que la potencialidad del conflicto político, social y racial era algo más que un peligro inminente para todo el edificio constitucional americano. Por lo mismo, el clima de presiones existentes en la sociedad, necesariamente, se trasladó al seno de la Corte. Robert Burt explica con lujo de detalles esa dimensión conflictiva, al punto de atribuir a uno de los jueces -Hugo Black- un papel de aterrorizador e intimidador de los demás jueces. Claramente, esa notable Suprema Corte americana -integrada, entre otros, por Frankfurter y Jackson- sabía que su decisión no iba a producir satisfacción e iba a ser duramente cuestionada. Sin embargo, optaron por un camino que intenta ignorar las consecuencias o que las sustrae al papel exacto que éstas tengan. Así, avanzaron en lo que es propio de las democracias, "dejar que las consecuencias de aquella sentencia sean sometidas a nuevos debates aunque en intervalos indeterminados y repetidos en forma múltiple”. ${ }^{4}$ Justamente ese ha sido el papel y función que han cumplido los sucesivos fallos del Excmo. Tribunal Constitucional en las acciones de inaplicabilidad desde el caso de Silvia Peña vs. ING Salud hasta la fecha. Han pasado largos dos años con el tema puesto en discusión. Esta misma demostración de la secuencia del debate es el mentís más significativo frente a la exageración del descalabro, de caída del sistema, de devaluación del régimen privado de salud, de demolición de la iniciativa privada en salud y de cuanta retórica quiera hacerse para defender esta discriminación. Los jueces americanos en sus deliberaciones frente a un caso angustioso y verdaderamente límite, llegaron a una conclusión históricamente cierta: "una decisión de la Corte que invalide (leyes estaduales) no traerá aparejada la transición social. Es obvio que nuestra decisión no pone fin sino que marca el comienzo de la lucha en torno a la segregación" 5 .

Por ello, es evidente que estamos frente a un comienzo de tomarnos los derechos fundamentales con toda la seriedad que esto implica y con toda la extensión que de ellos se derivan. Los derechos constitucionales no requieren de la interpositio legislatoris para que tengan validez. Tienen validez por sí mismo, son directamente aplicables y se reclama para sí la defensa de ese núcleo intangible que constituye el contenido esencial del derecho. En consecuencia, puede afirmarse con claridad que, dentro de dicho contenido esencial, la discriminación arbitraria resulta inconstitucional.

${ }^{4}$ BurT, Robert (2000): Constitución y Conflicto (Eudeba, Departamento de Publicaciones de la Facultad de Derecho de la Universidad de Buenos Aires, Primera Edición), p. 386.

${ }^{5}$ BuRT, Robert (2000), p. 387. 


\subsubsection{La reforma constitucional frustrada (Boletin $N^{\circ}$ 6221-07)}

Después de las reformas constitucionales del 2005, que establecieron las atribuciones del Tribunal Constitucional en el artículo $93 \mathrm{~N}^{\circ} 6$ y N $\mathrm{N}^{\circ} 7$, han existido iniciativas que tienden a morigerar los efectos de dicha reforma. Justamente éstas pusieron hincapié en las consecuencias de declarar inconstitucional un precepto legal.

Es así como una moción parlamentaria (Boletín $\mathrm{N}^{\circ}$ 6621-07) pretendió establecer un plazo de un año para la entrada en vigencia del Fallo del Tribunal Constitucional que hubiere declarado la inconstitucionalidad de una ley. Con ello, se pretendía crear una especie de período de creación normativa para que el Congreso Nacional regulara la materia que quedaría no cubierta con la inconstitucionalidad. Una reforma de esta naturaleza no prosperó por múltiples razones; pero, entre otras, porque imponía al Tribunal Constitucional que prefigurara las razones por las cuales había que legislar. Es decir, ponía un énfasis superlativo en las consecuencias jurídicas y extendía los mandatos del Tribunal a ser una especie de eslabón del proceso legislativo, pasando de un examen de constitucionalidad a una verdadera idea o iniciativa de legislar. Es evidente que un plazo de esa naturaleza podía generar el efecto adverso, que es el propiciar la declaración de mayores inconstitucionalidades que las que verdaderamente existían, puesto que significaba dejarle al Congreso la tarea de resolver el problema. No obstante, una declaración de inconstitucionalidad por el mayor de los quórums constitucionales que tiene el ordenamiento es suficiente cautela de la deferencia del legislador. Y ello lleva a no mirar las consecuencias sino como el inicio de un proceso de debate que el legislador debe resolver, se demore lo que se demore.

\subsection{La inexistencia de laguna}

\subsubsection{Conceptualización de las lagunas jurídicas}

En otro plano argumentativo, las ISAPRES han sostenido que la declaración de inconstitucionalidad del artículo 38 ter implicará la consagración de una "laguna jurídica" que impediría el funcionamiento del sistema o que lo entrabaría de tal manera, toda vez que le restaría la estructura de medición del riesgo para una empresa dedicada a los seguros.

Las lagunas se producen cuando el juez no puede resolver un problema planteado por ley. ${ }^{6}$ De estas lagunas la doctrina distingue cuatro tipos:

${ }^{6}$ Calvo García, Manuel (ed.) (1995): Interpretación y argumentación jurídica. Trabajos del Seminario de Metodología Jurídica Vol. I (Prensas Universitarias de Zaragoza, Primera Edición), p. 124. 
En primer lugar, se puede decir que existen lagunas verdaderas o propias cuando la ley sólo da al juez una orientación general, señalándose expresa o tácitamente hechos, conceptos o criterios no determinados en sus notas particulares y que el juez debe estimar e investigar para el caso concreto (laguna técnica). También se da una laguna verdadera cuando la ley calla en absoluto, ya intencionadamente, ya porque no se previó el caso, ya porque de ningún modo podía resolverse, por no suscitarse la cuestión hasta después de dictada (laguna normativa). También se puede hablar de lagunas lógicas, de conflicto, de colisión. Estas se producen cuando hay dos leyes que se contradicen, haciéndose reciprocamente ineficaces. Además existen también las llamadas lagunas axiológicas, criticas, ideológicas, de lege ferenda of falsas, que aparecen cuando una norma es inaplicable por abarcar casos que el legislador no habria ordenado de haber conocido aquéllos. ${ }^{7}$

De la descripción de las lagunas surge con nitidez que, en la presente causa, no nos encontramos frente a una laguna normativa, puesto que la ley regula el asunto y no lo omite.

Tampoco nos encontramos frente a una laguna lógica, puesto que no hay dos leyes que se vuelven ineficaces por sus contenidos diferenciados. En un cierto sentido, se podría argumentar que es una laguna técnica puesto que deliberadamente se reguló lo principal por ley y se abandonó su complemento a una norma reglamentaria -instrucciones generales de la Superintendencia- y que vendría a ser cuestionado cuán complementario resultaba la regulación hecha por la Superintendencia de ISAPRES.

\subsubsection{La falsa laguna o laguna axiológica}

No obstante lo señalado precedentemente, parece más claro situarse frente a una falsa laguna, toda vez que el legislador no pretende crear esta discriminación por ley. No sería razonable atribuirle al legislador la determinación legal de una discriminación de esta naturaleza. Por razones axiológicas derivadas del ámbito dentro del cual puede legislar el Congreso Nacional, es evidente que existe un contenido esencial indisponible a sus mandatos. El artículo $19 \mathrm{~N}^{\circ} 2$ inciso final de la Constitución Política de la República establece que "ni la ley ni autoridad alguna podrán establecer diferencias arbitrarias". Con ello se descarta plenamente la idea de que pudiese configurarse una laguna técnica, puesto que la "autoridad", en este caso la Superintendencia de ISAPRES, también está indisponible para la regulación de una discriminación. Más adelante, analizaremos el tópico de la reserva legal, pero por ahora nos basta acreditar la imposibilidad que aquello suceda.

${ }^{7}$ Calvo García (1995), p. 124. 


\subsubsection{El problema del ordenamiento, no de la norma}

Por lo demás, la creencia de que nos podríamos encontrar frente a una laguna nos lleva a recordar los fundamentos más básicos de la teoría del Derecho. El destacado jurista Norberto Bobbio destacaba la diferencia entre la teoría de la norma jurídica y la teoría del ordenamiento jurídico. A veces, como resulta el ejemplo que analizamos, "un problema mal resuelto en el plano de la norma individual encuentra una solución más satisfactoria en el plano del ordenamiento". ${ }^{8}$ Es evidente que la dimensión del ordenamiento que aquí está presente es el orden constitucional y cuando se afecta un derecho fundamental, como la igualdad de trato, no es posible concebir que nos encontremos frente a una laguna. Allí lo que hay es la aplicación de un principio constitucional que expulsa a una norma inconciliable con el principio. No existen lagunas en el constitucionalismo, puesto que siempre es posible derivar un artículo constitucional hacia la interpretación de un caso. "Si el Derecho fuera sólo un sistema de reglas, las lagunas serían inevitables, como también lo sería la libre creación judicial, pero el sistema es cerrado en la medida que siempre hay principios a los que puede recurrirse y, por lo tanto, no hay en él ningún caso posible que no pueda ser decidido sobre la base de criterios jurídicos". ${ }^{9}$ Por ende, tratándose de un caso de igualdad, entre otros derechos fundamentales, que se conecta con valores esenciales como la dignidad humana, según las propias sentencias del Excmo. Tribunal Constitucional, en la materia que vemos, no puede sino prevalecer una discusión desde el ámbito de los principios.

\subsection{La renuncia de derechos fundamentales}

Dentro del plano de las consecuencias puede analizarse la perspectiva contraria a la seguida por el Excmo. Tribunal Constitucional en sus votos de mayoría en las acciones de inaplicabilidad por inconstitucionalidad. ¿Qué pasa si el Tribunal no reúne el quórum suficiente para declarar la inconstitucionalidad del artículo 38 ter de la Ley $\mathrm{N}^{\circ} 18.933$ ?

No se trata en este punto de estudiar la subsistencia de las acciones de inaplicabilidad como recurso remedial frente a una discriminación. La pregunta es otra para el ámbito de los derechos fundamentales. ¿¿Trae aparejada alguna consecuencia jurídica en la limitación de derechos fundamentales la tesis de acoger la constitucionalidad de la norma?

\footnotetext{
${ }^{8}$ Bobbio, Norberto (1996): Teoría general del derecho (Debate, Madrid, Cuarta Reimpresión), p. 160.

9 Prieto Sanchís, Luis (1997): Constitucionalismo y positivismo (Fontamara, México), p. 21.
} 
A nuestro juicio, sí. La constitucionalidad reivindicaría el accionar de las ISAPRES mediante un ejercicio abusivo de la libertad contractual que se pretendía limitar. En otro apartado de este alegato, hacemos la reflexión acerca de la concurrencia y ponderación de la libertad de elegir entre el sistema público y privado de salud, la libre iniciativa empresarial de las ISAPRES y la libertad de negociación contractual entre éstas y sus afiliados.

No obstante, queremos ir a un punto más preciso. Es perfectamente posible que si el Tribunal admite la constitucionalidad de la norma, se produzca la autorización para proceder a la renuncia de derechos fundamentales por vía contractual. Con ello, se produciría una limitación fáctica de los derechos fundamentales. Recordemos con Joaquín Brage Camazano que las limitaciones de los derechos fundamentales no sólo pueden provenir de la restricción que realice el legislador o la autoridad administrativa, sino que también abarca a los fallos de los Tribunales de Justicia y Constitucionales. ${ }^{10}$ En este entendido, se asume la tesis amplia sostenida por la mayoría de la doctrina en orden a identificar que las restricciones de los derechos fundamentales designan "cualesquiera medidas, de alcance general o particular, que reducen el ámbito de aplicabilidad del derecho". ${ }^{11}$

¿Por qué puede producirse una renuncia de derechos fundamentales en este caso y en qué consistiría?

Lo primero es acreditar este hecho, el propio artículo 34 de la Ley $\mathrm{N}^{\circ}$ 18.933, y como vía de ejemplo, estructura la posibilidad de celebrar contratos con personas no cotizantes de un sistema previsional ${ }^{12}$.

Por ende, dentro de las reglas de libre contratación están las normas que enjuiciamos del artículo 38 ter.

La renuncia de derechos fundamentales es una materia que ha tratado el Tribunal Constitucional chileno, pero no de una manera sistemática. Entre otros casos, cabe destacar el fallo de 8 de septiembre de 2009 en donde acredita los elementos consustanciales de un contrato de salud, el cual incorpora reglas de derecho público.

El Tribunal en su considerando Quincuagésimo primero sostiene que:

\footnotetext{
${ }^{10}$ Brage Camazano, Joaquín (2004): Los limites a los derechos fundamentales (Madrid, Dykinson).

${ }^{11}$ Díez-Picazo, Luis María (2005): Sistema de derechos fundamentales (Thomson, Civitas, Segunda Edición, Madrid), p. 107.

${ }^{12}$ Artículo 34.- Las instituciones de salud previsional, podrán celebrar contratos de salud con personas que no se encuentren cotizando en un régimen previsional o sistema de pensiones. Estos contratos se regirán por las disposiciones de esta ley en cuanto les sean aplicables y en especial por lo dispuesto en los artículos 26, $27,28,33,38,38$ bis y 38 ter.
} 
[...] conforme se ha observado, lo dispuesto en el numeral $9^{\circ}$ del artículo 19 de la Constitución Política de República, configura la base de orden público incorporada a todo contrato de salud previsional y que, como tal, no puede ser restringida o aminorada por la ley ni por cláusula contractual alguna sino al contrario, aquéllas deben, como manifestación de la fuerza normativa que singulariza a la Constitución -que afecta igualmente las relaciones contractuales entre particulares-, no sólo respetar lo previsto en el citado precepto constitucional, sino que, además, promover cada uno de sus imperativos.

Dicho de otra manera, por acuerdo consensual entre las partes, por más que valga como ley según lo dispuesto en el artículo 1545 del Código Civil ${ }^{13}$, no se pueden sustraer contenidos materiales de rango constitucional disminuyendo el alcance de un derecho fundamental.

\subsection{1. ¿Renuncia general o particular a un derecho determinado? Condiciones de la renuncia particular}

El tema de la renuncia de derechos ha sido materia de estudio por la doctrina civilista, la cual ha entendido que se puede renunciar a un derecho siempre que no contraríe el interés, el orden público ni perjudique a terceros. Nuestro Código Civil indica en el artículo 12 que "podrán renunciarse los derechos conferidos por las leyes, con tal que sólo miren al interés individual del renunciante, y que no esté prohibida su renuncia". No obstante, "la doctrina civilista suele sostener que los derechos de la personalidad son irrenunciables; y cabe a estos efectos, habida cuenta de su común ratio garantista, una asimilación entre los conceptos de derechos de la personalidad y de derechos fundamentales. Habría que concluir, pues, que los derechos fundamentales son irrenunciables". ${ }^{14}$

Parecería, entonces, que la mera declaración de establecer que las normas sobre derechos constitucionales o fundamentales son de orden público y, por tanto, no negociables en el marco contractual; resolvería de raíz el problema que suscitaría la constitucionalidad de la norma impugnada. La dificultad estriba en un antecedente adicional. Lo que no es admisible es la renuncia general a un derecho en donde previa e indeterminadamente uno abdica de un ejercicio de conductas consustanciales a la dignidad, libertad e igualdad humanas. Sin embargo, la renuncia a un derecho a un caso concreto es parte consustancial de las libertades humanas, sin que medie un criterio paternalista de por medio. Por lo demás, sucede todos los días. Nadie reivindica sus derechos sistemáticamente al ciento por ciento, puesto

\footnotetext{
${ }^{13}$ Art. 1545. Todo contrato legalmente celebrado es una ley para los contratantes, y no puede ser invalidado sino por su consentimiento mutuo o por causas legales.

${ }^{14}$ Díez-Picazo (2005), p. 141.
} 
que la dimensión judicializadora de la vida cotidiana puede resultar intolerable. Por lo mismo, "los derechos fundamentales son derechos subjetivos y éstos se caracterizan por dejar a su titular la facultad de hacer valer, cuando lo estime oportuno, la protección de los intereses protegidos por aquéllos". ${ }^{15}$. No obstante, esta cláusula tiene limitaciones y uno de los autores que ha puesto énfasis en esta materia reconoce dos criterios que nos llevan a excluir claramente el caso del artículo 38 ter de la Ley No 18.933.

Es así como uno puede renunciar siempre que de ello no se beneficie el Estado. Lo anterior, sería la degradación de los derechos constitucionales y la inversión del principio que "el Estado está al servicio de la persona humana" (artículo $1^{\circ}$ inciso $4^{\circ}$ de la CPR). En este caso se produce tal beneficio, puesto que al restringirse la libertad del usuario de una Isapre terminan las personas "escogiendo" el sistema estatal de salud. Esta ausencia de libertad desemboca en una restricción no aceptable. Y el segundo criterio que pone Luis María Díez-Picazo es que la renuncia sea esencialmente revocable. ${ }^{16}$ Como se trata de un ejercicio de un derecho fundamental, siempre está dentro de su órbita jurídica el retomar el ejercicio de sus derechos naturales. Sin embargo, tratándose de una materia contractual como la existente entre una Isapre y su afiliado, en donde se rigen bajo fórmulas de contratos de adhesión, la posibilidad de la revocabilidad está descartada. No existen perspectivas posibles de renegociar las reglas contractuales y, dentro de ellas, la evolución que tienen factores como la edad o el sexo en el costo de los planes de salud.

Por tanto, las perspectivas de posibles reconocimientos de la constitucionalidad del artículo 38 ter de la Ley $\mathrm{N}^{\circ} 18.933$ implicaría abrir las consecuencias jurídicas de la renuncia de derechos fundamentales. La propia jurisprudencia del Tribunal Constitucional advertía de las razones por las cuales era irrenunciable, pero sus efectos para el caso concreto eran necesarios de precisar. Es evidente que el principio de la dignidad humana, los derechos constitucionales y, dentro de ellas, las reglas de igualdad, y el derecho de protección a la salud son consustanciales a configurar un derecho de salud con contenidos contractuales más fuertes que aquellos que resultasen de la mera negociación entre las partes. Que, si bien, existe una limitada perspectiva de renuncia a los derechos fundamentales no es aplicable al caso concreto que analizamos y, desde un punto de vista abstracto, constituiría una renuncia general que es repudiada por la doctrina civilista y constitucionalista.

${ }^{15}$ Díez-Picazo (2005), p. 142.

${ }^{16}$ Díez-Picazo (2005), p. 143. 


\section{LA VIOLACIÓN DE LA RESERVA LEGAL}

El Excmo. Tribunal Constitucional ha declarado en cuatro casos la inaplicabilidad del artículo 38 ter de la Ley $\mathrm{N}^{\circ}$ 18.933. La argumentación se ha centrado en un conjunto amplio de derechos fundamentales que fundamentan plenamente su inaplicabilidad al caso concreto. No obstante, del juicio de inaplicabilidad no se puede señalar la certeza de que todos los casos tengan una identidad que lleve al mismo resultado. Dicho de otra manera, la dimensión abstracta del juicio de inconstitucionalidad supone descartar, tanto prima facie como definitivamente, la perspectiva y posibilidad de que algunos de sus contenidos se encuadre dentro de la Constitución. La inconstitucionalidad debe ser manifiesta, clara y amplia como el quórum que se exige para declararla. Creemos que esa situación se da, en primer lugar, por la violación del principio de reserva legal respecto del desarrollo del principio de igualdad.

La tesis que explicaremos es que el artículo 38 ter no cumple con los estándares constitucionales exigidos en materia de respeto al principio de reserva legal en el desarrollo de derechos fundamentales.

El Excmo. Tribunal Constitucional ha tenido un tratamiento sistemático de la relación entre ley y reglamento, al punto de ser una de las materias más emblemáticas de su jurisprudencia. Como es conocida la evolución del Tribunal ha tenido dos momentos diversos respecto de la relación entre ley y reglamento. Por una parte, estuvo el debate inicial en torno al dilema de reserva absoluta o relativa de ley. Esta discusión se zanjó de manera casi definitiva a favor de la tesis sobre la reserva legal relativa. ${ }^{17}$ En esta jurisprudencia se admitió un aporte doctrinal que distinguía la existencia de varias reservas legales y no una modalidad genérica de reserva. Por lo mismo, en la Sentencia Rol No 254 se reconoció la existencia de esta variedad de reservas legales relativas y se justificó la necesidad de decretos o reglamentos que bajo la razonabilidad técnica permitieran darle viabilidad a los contenidos prácticos de una ley. ${ }^{18}$

\footnotetext{
${ }^{17}$ Existe la discusión acerca del denominado falso precedente de la Sentencia del Tribunal Constitucional de 1994, relativo a la restricción vehicular en donde se volvió a determinar la vigencia de la teoría absoluta de la reserva de ley a través de la cual se impide normar un derecho o restringir una actividad mediante una norma administrativa. Ver Ministerio Secretaría General de la Presidencia (2010): Doctrina Constitucional del Presidente Ricardo Lagos Escobar (2000-2006). Tomo I (Santiago, Gobierno de Chile, Editorial LOM), pp. 111-118.

${ }^{18}$ Uno de los promotores de esta teoría es quien acompaña los argumentos a este documento de téngase presente y que se sostuvieron desde 1996. Ver García Pino, Gonzalo (2004): La Reserva Legal de Derechos Constitucionales: ¿Poder Legislativo contra la Administración? (Santiago, Colección de Investigaciones Jurídicas, $\mathrm{N}^{\circ}$ 5, Universidad Alberto Hurtado). Esta historia doctrinaria y jurisprudencial está recogida en ZAPATA Larraín, Patricio (2008): Justicia Constitucional. Teoría y Práctica en el Derecho Chileno y Comparado (Edi-
} 
Sin embargo, esta flexibilidad en la colaboración reglamentaria para acompañar las disposiciones que reglan un derecho fundamental no se puede hacer al margen de los criterios que ha sostenido el Tribunal Constitucional. La diversidad de reservas legales ha dado paso a la discusión acerca de cuál es la mejor manera de reforzar ciertos contenidos de algunas reservas legales. Es así como se distingue la presencia de cuatro tipos de reservas que se asocian a la concretización o desarrollo de los contenidos normativos de una ley. Esta conceptualización se hace al amparo del artículo $19 \mathrm{~N}^{\circ} 26$ que establece el respeto al contenido esencial de los derechos. Es así como se ha propuesto la distinción de las reservas legales regulatorias, complementarias, limitativas y negativas. ${ }^{19}$

Cuando analizamos el caso del artículo 38 ter, ‘a cuál reserva legal nos estamos refiriendo?

Para ello hay que describir los artículos de esta ley involucrados. Por una parte, está el artículo $2^{\circ}$ letra $n$ ) que define algunos términos de la ley de ISAPRE y, entre ellos, la denominada "tabla de factores". Se entiende por

aquella tabla elaborada por la Institución de Salud Previsional cuyos factores muestran la relación de precios del plan de salud para cada grupo de personas, según edad, sexo y condición de cotizante o carga, con respecto a un grupo de referencia definido por la Superintendencia, en instrucciones de general aplicación, el cual asumirá el valor unitario. Esta tabla representa un mecanismo pactado de variación del precio del plan a lo largo del ciclo de vida, el que es conocido y aceptado por el afiliado o beneficiario al momento de suscribir el contrato o incorporarse a él, según corresponda, y que no podrá sufrir variaciones en tanto la persona permanezca adscrita a ese plan.

En este artículo se sostiene que esta tabla se elabora por cada ISAPRE, pero bajo "instrucciones de general aplicación" de la Superintendencia de ISAPRES. En esta normativa administrativa se debe precisar el "grupo de referencia" que resulta identificado de un conjunto de factores, dentro de los cuales está la edad, el sexo y la condición de cotizante o carga. Por ahora, este artículo nos permite definir la naturaleza de la reserva legal.

Por lo anterior, es que el artículo esencial es el que se impugna en este proceso. ¿Qué nos dice el artículo?

Artículo 38 ter.-Para determinar el precio que el afliado deberá pagar a la Institución de Salud Previsional por el plan de salud, la Institución deberá aplicar a los precios base

torial Jurídica de Chile, Santiago), pp. 523-525 y Carmona Santander, Carlos (1998-1999): “Tendencias del Tribunal Constitucional en la Relación Ley-Reglamento", en Revista de Derecho Público (Volumen 61, 1998/1999), pp. 180-193.

${ }^{19}$ GarCÍA Pino (2004), p. 170. 
que resulten de lo dispuesto en el artículo precedente, el o los factores que correspondan a cada beneficiario, de acuerdo a la respectiva tabla de factores.

La Superintendencia fijará, mediante instrucciones de general aplicación, la estructura de las tablas de factores, estableciendo los tipos de beneficiarios, según sexo y condición de cotizante o carga, y los rangos de edad que se deban utilizar. Cada rango de edad que fije la Superintendencia en las instrucciones señaladas en el inciso precedente se sujetará a las siguientes reglas:

1.- El primer tramo comenzará desde el nacimiento y se extenderá hasta menos de dos años de edad.

2.- Los siguientes tramos, desde los dos años de edad y hasta menos de ochenta años de edad, comprenderán un minimo de tres años y un máximo de cinco años.

3. - La Superintendencia fijará, desde los ochenta años de edad, el o los tramos que correspondan.

4.- La Superintendencia deberá fijar, cada diez años, la relación máxima entre el factor más bajo y el más alto de cada tabla, diferenciada por sexo.

5. - En cada tramo, el factor que corresponda a una carga no podrá ser superior al factor que corresponda a un cotizante del mismo sexo.

En el marco de lo señalado en el inciso precedente, las Instituciones de Salud Previsional serán libres para determinar los factores de cada tabla que empleen. En todo caso, la tabla de un determinado plan de salud no podrá variar para los beneficiarios mientras se encuentren adscritos al mismo, ni podrá alterarse para quienes se incorporen a él, a menos que la modificación consista en disminuir de forma permanente los factores, total o parcialmente, lo que requerirá autorización previa de la Superintendencia; dicha disminución se hará aplicable a todos los planes de salud que utilicen esa tabla.

Cada plan de salud sólo podrá tener incorporada una tabla de factores. Las Instituciones de Salud Previsional no podrán establecer más de dos tablas de factores para la totalidad de los planes de salud que se encuentren en comercialización.

Sin perjuicio de lo dispuesto en el inciso precedente, las Instituciones de Salud Previsional podrán establecer nuevas tablas cada cinco años, contados desde las últimas informadas a la Superintendencia, manteniéndose vigentes las anteriores en los planes de salud que las hayan incorporado.

Las Instituciones de Salud Previsional estarán obligadas a aplicar, desde el mes en que se cumpla la anualidad y de conformidad con la respectiva tabla, el aumento o la reducción de factor que corresponda a un beneficiario en razón de su edad, y a informar al cotizante respectivo mediante carta certificada expedida en la misma oportunidad a que se refiere el inciso tercero del artículo 38.

No es del caso explicar este artículo en su globalidad, sino que aquellos elementos que interesan.

Primero, en estricto rigor los elementos que determinan el precio final de un plan supone la combinación de tres criterios: edad, sexo y si es carga o cotizante. 
Esto no es menor, porque la ley hace un juicio de igualdad en los tres casos y no en los dos que se suelen impugnar. Lo anterior, tiene toda lógica porque el criterio comparativo que utiliza el legislador en el caso de cotizante o carga es una relación comparativa "entre ellos" y esa relación es razonable y proporcional, porque lo lleva a establecer "en la ley" que una carga no puede tener un costo superior a un cotizante. Con ello, si bien no termina de precisarse los costos definitivos, porque aún falta considerar los criterios de edad y sexo, sí nos ilumina que el legislador cumplió su tarea en esa parte.

Segundo, lo anterior aísla sólo los elementos "edad" y "sexo" como las categorías "sospechosas" y de escrutinio estricto. Para ello la ley establece que "la Superintendencia fijará, mediante instrucciones de general aplicación, la estructura de las tablas de factores, estableciendo los tipos de beneficiarios, según sexo y condición de cotizante o carga, y los rangos de edad que se deban utilizar". Definidas esas tablas y al interior de las mismas "las Instituciones de Salud Previsional serán libres para determinar los factores de cada tabla que empleen".

Por ende, nos encontramos frente a una materia que regula el establecimiento de una diferencia basada en edad y sexo que pretende no ser arbitraria. Dicho de otra manera, se trata de un asunto regulado por el inciso final del artículo $19 \mathrm{~N}^{\circ} 2$. En la distinción de reservas que hemos hecho este artículo está clasificado dentro de aquellas materias que suponen ser una "reserva legal negativa". ${ }^{20}$

Como no resulta claro cuándo nos encontramos frente a una prohibición y puede admitirse plenamente la existencia de una colaboración reglamentaria, a lo menos hay que sostener que nos encontramos frente a la reserva más exigente, aquélla en donde el legislador debe prever todas las circunstancias que no redunden en una limitación y afectación esencial del derecho.

Para determinar con exactitud si cumple o no con los requisitos que permiten enjuiciar plenamente que nos encontramos frente a una norma admisible constitucionalmente, estudiaremos los elementos que ha puesto la doctrina y la jurisprudencia constitucional.

A efectos de tener una colaboración reglamentaria en forma, la doctrina ha exigido la presencia de una previa cobertura legal -cuestión que se cumple en este caso. Por otro lado, se exige que cumpla efectivamente con la ejecución de una ley. Dentro de ella, Francisco Zúniga ha establecido que, a lo menos, "debe paliar las deficiencias eventuales de la propia ley". ${ }^{21}$

\footnotetext{
${ }^{20}$ García Pino (2004), p. 194.

${ }^{21}$ ZúNiga Urbina, Francisco: "Ley y reglamento en la jurisprudencia del Tribunal Constitucional (del afrancesamiento a la germanización)", ponencia no publicada.
} 
En este punto resulta sorprendente la determinación del factor edad por parte del legislador. Salvo la determinación del rango etáreo hasta los dos años y el superior a los ochenta años que resulta clara, simplemente nos encontramos frente a un mandato que sugiere la abierta deslegalización en el rango etáreo que va desde los $¡^{2}$ hasta los 80 años! Esta es una materia que la abandona al complemento normativo de la Superintendencia de ISAPRES. ¿Cabe paliar tal deficiencia en una reserva legal negativa que puede establecer una discriminación arbitraria mediante norma administrativa de aplicación enteramente libre por parte de las ISAPRES? A nuestro juicio, no es posible, y es aquí donde reside la inconstitucionalidad flagrante.

No obstante, hay más elementos de juicio que nos permiten fundamentar esta inconstitucionalidad y para ello recurriremos a la jurisprudencia del propio Tribunal en la causa Rol No 335. Ahí estableció tres requisitos para examinar la ponderación en el cumplimiento de la normativa administrativa que regula elementos limitativos de un derecho. Por una parte, exige norma legal habilitante previa, cuestión que ya advertimos se cumple en la especie. En segundo lugar, que no afecte el núcleo esencial del derecho. Aquí ya hemos sostenido que por tratarse de la regulación de una prohibición o reserva legal negativa, su propia determinación normativa llevó a tornar impracticable la libertad de elegir entre el sistema público o privado de salud (artículo $19 \mathrm{~N}^{\circ}$ 9, inciso final de la CPR). Y, finalmente, que se trate de un límite determinado del derecho fundamental. Pues bien, la norma legal habilitante otorga un rango amplísimo en materia de edad y produce una autorización indeterminada para regular el derecho en circunstancias que sus potestades eran perfectamente acotadas.

Sin perjuicio de lo anteriormente señalado, debe recordarse que, cuando la Comisión de Estudios de la Nueva Constitución trató lo que debía comprenderse como "materias propias de ley" dispuso que los asuntos "[...] laborales, sindicales, previsionales y de seguridad social que estuvieren regladas en leyes de importancia, codificadas o no codificadas, no pudieran ser modificadas por un simple decreto" 22 .

Todo este conjunto de argumentos nos lleva a sostener que no cumple en la especie con satisfacer los requisitos constitucionales básicos para configurar una reserva sobre una materia que exige escrutinio estricto como la determinación de una diferencia no arbitraria basada en sexo o edad. Resulta claro que la norma legal afecta en la esencia el derecho, puesto que torna una libertad en impracti-

${ }^{22}$ Comisión de estudio de la nueva Constitución Política de la República (1978): Actas Oficiales (Sesión 409a; 10 de agosto de 1978). 
cable y la deslegalización degenera el derecho a la igualdad transformándolo en una discriminación. En consecuencia, el artículo 38 ter de la Ley $\mathrm{N}^{\circ} 18.933$ debe declararse inconstitucional.

\section{LA DISCRIMINACIÓN ARBITRARIA POR SEXO Y EDAD}

\subsection{El principio de igualdad y no discriminación arbitraria}

El principio de igualdad tiene una doble configuración: como principio jurídico objetivo y como derecho subjetivo. Su carácter objetivo está relacionado con el imperativo que recae sobre los poderes públicos de proteger el contenido de este derecho, constituyéndose como ente primariamente obligado y limitado, el poder legislativo, el cual deberá evitar la existencia de normas que establezcan tratos discriminatorios, abogando por la superación de las condiciones factuales de desigualdad en busca de la igualdad sustancial o material ${ }^{23}$.

El principio de igualdad otorga el derecho de carácter subjetivo de exigir un trato igual. Desde esta perspectiva lógico-subjetiva, el principio de igualdad tiene un carácter relacional, precisando normas, situaciones y relaciones jurídicas. Se funda en una pluralidad de entidades que se relacionan entre sí, de modo que sino hay nexo relacional no hay igualdad que analizar ${ }^{24}$. Para efectuar un juicio de igualdad es necesaria una base sobre la cual comparar las situaciones y poder establecer la existencia o no de diferencias de trato, requiriéndose en consecuencia un tertium comparationis (término de comparación), esto es, "indicar los supuestos de hechos con los que se ha de comparar aquél en que el recurrente se encuentra a fin de verificar si ha existido o no la discriminación que alega" ${ }^{25}$. Se efectúa un examen definiendo si existen decisiones o acciones que producen diferencias entre personas, grupos de personas o cosas similares o con elementos comunes, por medio de una comparación entre ellas ${ }^{26}$. En definitiva, y en razón del principio de igualdad, se

${ }^{23}$ Gavara de Cara, Juan Carlos (2004): “El Principio de Igualdad”, en Gavara de Cara, Juan Carlos (Ed.), Constitución, Desarrollo, Rasgos de Identidad y Valorización en el XXV Aniversario (1978-2003) (Institut de Ciences Polítiques i Socials, J. M. Bosch Editor, Barcelona, España), p. 71.

${ }^{24}$ Pérez Luño, Antonio E (2005): Dimensiones de la Igualdad (Instituto de Derechos Humanos Bartolomé de las Casas, Universidad Carlos III de Madrid, Fundación el Monte, Cuadernos "Bartolomé de las Casas" $\left.\mathrm{N}^{\circ} 34\right)$, p. 18.

${ }^{25}$ SuAy Rincón, José (1985): El principio de Igualdad en la Justicia Constitucional (Instituto de Estudio de Administración Local, Madrid), p. 154.

${ }^{26}$ Gavara de Cara (2004), pp. 62 y 63. Vid. Gavara de Cara, Juan Carlos (2005): Contenido y función del término de comparación en la aplicación del principio de igualdad (Thomson Aranzadi, Navarra), p. 36. En relación al término de comparación Pérez Luño sostiene: "La relación de igualdad se explicita en la comparación entre los entes de los que se predica. Se precisa contar, por ello, con un elemento que haga 
debe velar por la no existencia de leyes de tipo particulares en contraposición de la abstracción requerida de las normas jurídicas, no impidiendo la posibilidad de disponer de normas específicas que comprendan a una categoría concreta de personas, exigiéndose una plena justificación de la especialidad de la ley.

Bajo este marco, cabe examinar el principio de igualdad en la ley y la posibilidad de disponer tratamientos diferenciados que aparentemente vulnerarían esta igualdad de derecho. El respeto primario a la igualdad está fundado en el aforismo de origen filosófico platónico-aristotélico que hay que "tratar igualmente a los iguales", imposibilitando al legislador de establecer normas que atenten contra esta igualdad formal. Junto a este postulado de carácter general, tiene cabida la continuación del aforismo precedente que indica que debe "tratarse desigualmente a los desiguales", es decir, que frente a situaciones de hecho es posible disponer de normas que afecten al principio de igualdad formal, consagrando disposiciones que dispongan una desigualdad de trato.

El tratamiento diferenciado es una regla de excepción, pues, primariamente debe concurrir como modelo de aplicación el principio de igualdad como no diferenciación, procediendo la desigualdad normativa únicamente cuando esté justificada ${ }^{27}$. Así, el principio de igualdad se desarrolla por dos vías derivadas del

posible la comparación: un tertium comparationis. Esto equivale a decir que dos o más entes iguales, es decir, pertenecen a una misma clase lógica, cuando en ellos concurre una cualidad común, el tertium comparationis que opera como elemento definitorio de la clase y son desigualdades cuando tal circunstancia no se produce. La determinación de este término de comparación es básica para calificar a dos o más entes como iguales. La exigencia de un juicio comparativo se explicita en la necesidad de establecer qué entes y qué aspectos de los mismos van a considerarse relevantes a efectos de la igualdad”. Vid. Pérez LuÑo (2005), p. 18.

${ }^{27}$ Para Robert Alexy, la desigualdad normativa está justificada cuando existen "razones suficientes" que justifique la diferencia. La igualdad es la regla general, por cuanto, si no existe razón suficiente para desigualar deberá aplicarse un tratamiento igual, pero, en caso de concurrir razones jurídicas suficientes deberá disponerse la diferenciación normativa. Para saber cuándo existe una razón suficiente que justifique un tratamiento diferenciado, Alexy construye un modelo abstracto basado en la teoría de los principios. Para justificar la existencia de la igualdad de hecho, y darle el carácter de derecho subjetivo, atribuye a la desigualdad de hecho la forma de principio, otorgándole significación y valor jurídico a la igualdad de hecho, de manera que el "principio de la igualdad de hecho" será razón suficiente para constituir un derecho subjetivo a la desigualdad de iure y se constituya como fundamento para la creación de la igualdad de hecho, "sólo si desplaza a todos los otros principios opuestos que estén en juego" (entre ellos, el principio de igualdad de iure; principio formal de libertad de formación del legislador democráticamente legitimado, pues el Tribunal Constitucional (TC) limitará claramente la libertad normativa del legislador, por cuanto el TC es quien hace la valoración y la exigencia al legislativo para hacer efectiva la igualdad de hecho; principios vinculados a libertades negativas, etc.). De esta forma, existe una "razón suficiente" cuando la igualdad de hecho (considerada como principio) tiene prioridad ante todos los demás principios opuestos relevantes. Vid. AlexY, Robert (1993): Teoría de los Derechos Fundamentales (Centro de Estudios Políticos y Constitucionales, Madrid), pp. 395-414. Gregorio Peces-Barba utiliza el concepto de "relevancia" para indicar la calidad de las razones que se deben aducir para permitir un trato diferenciado. Para hacer posible la igualdad material, reflexiona el profesor Peces- 
contenido constitucional de este principio: la aplicación general del principio de igualdad con miras a evitar toda diferenciación injustificada que conlleve una discriminación prohibida, y por medio del tratamiento diferenciado entre las personas, estableciendo ciertas desigualdades normativas protectoras de ciertas personas o grupos de personas, con la finalidad de corregir situaciones de desigualdad factual ${ }^{28}$.

La Constitución Política en el art. $19 \mathrm{~N}^{\circ} 2$ consagra la igualdad ante la ley, que más bien se refiere a la igualdad en la ley, al exigir que los textos legales no deben contener materialmente distinciones subjetivas, representando un límite a la acción legislativa (como límite al poder) ${ }^{29}$ y al contenido de la ley. El texto constitucional se sitúa como una matriz de igualdad donde todos queden sujetos a un mismo ordenamiento ${ }^{30}$, imponiendo ciertas restricciones básicas al contenido legal, alineando la igualdad entre las personas, al no reconocer a personas o grupos privilegiados, declarando abolida la esclavitud, la igualdad de hombres y mujeres y la prohibición de la discriminaciones arbitrarias por parte de la ley y de la autoridad ${ }^{31}$.

El imperativo de igualdad representa la consagración de otra dimensión igualitaria referida la igualdad en la aplicación de la ley, donde se obliga al sujeto pasivo a evitar la comisión de acciones que provoquen situaciones de desigualdad.

Barba, deben consagrarse diferencias de trato, pero dichas fundamentaciones deben ser tales que permitan la diferenciación. La determinación de la "relevancia" es compleja desde la perspectiva teórica, debido a que "no estamos ante relaciones de hecho sino ante valoraciones que deben hacerse para fijar el ámbito de los contenidos normativos y las consecuencias jurídicas (en este caso, de diferenciación). (...) La relevancia o irrelevancia de las condiciones se ha planteado hasta ahora sólo en relación con hechos o circunstancias personales, que afectan a los contenidos de la relación jurídica pero, con el proceso de especificación de los derechos, la igualdad de trato formal como diferenciación se extiende también a la atribución de derechos a los titulares que, como hemos visto, se encuentran en inferioridad por razones culturales, físicas o de situación. Vid. Peces-Barba, Gregorio (1999): Curso de Derechos Fundamentales, Teoria General (Universidad Carlos III de Madrid, Boletín Oficial del Estado, Madrid), pp. 285-287.

${ }^{28}$ Jordán Díaz, Tomás (2008): La Protección de los Derechos Sociales: Modelos Comparados de Tutela Jurisprudencial (España y Chile) (Santiago, Colección de Investigaciones Jurídicas, $\mathrm{N}^{\circ} 10$, Universidad Alberto Hurtado 2006, publicada el 2008), pp. 98 y 99.

${ }^{29}$ Nogueira AlcalÁ, Humberto (1997): "El Derecho a la Igualdad en la Jurisprudencia Constitucional", en Revista de Derecho de la Universidad Católica de Valparaiso (Vol. XVIII, Actas de las XXVII Jornadas de Derecho Público), p. 170.

${ }^{30}$ Fernández González, Miguel Ángel (2001): Principio Constitucional de Igualdad ante la Ley (Editorial ConoSur, Santiago), p. 119.

${ }^{31}$ Textualmente establece el art. $19 \mathrm{~N}^{\circ}$ 2: "La igualdad ante la ley. En Chile no hay persona ni grupo privilegiados. En Chile no hay esclavos y el que pise su territorio queda libre. Hombres y mujeres son iguales ante la ley. Ni la ley ni autoridad alguna podrán establecer diferencias arbitrarias". 
La sustancialidad del numeral $2^{\circ}$ radica en la prohibición de discriminación arbitraria que veda una acción legislativa y de la autoridad carente de objetividad. Se ha entendido la arbitrariedad como un accionar contrario a la justicia o la razón, desproporcionado con relación a los objetivos perseguidos ${ }^{32}$, o aquella distinción contraria a la ética elemental o a un proceso de análisis intelectual ${ }^{33}$, cuya finalidad es "acrecentar la esfera de contenido que protege el derecho a la igualdad ante la ley y permitir un control estricto de las categorías distintivas contenidas en la ley, en cualquiera de sus formas" ${ }^{34}$.

El principio de igualdad en la ley se estructura sobre la clásica ordenación igualdad/desigualdad, consagrando la obligación de la prohibición de normas particulares o referidas a personas o grupos determinados (ley general y abstracta), prohibiendo al legislador establecer privilegios, diferenciaciones o desigualdades en la regulación normativa que efectúa basada en criterios irracionales, sin perjuicio de la posibilidad de disponer normas diferenciadas que establezcan distinciones normativas justificadas frente a situaciones o circunstancias que sitúa a los sujetos en posiciones de desigualdad comparativa, aunque se debe evitar la arbitrariedad en la distinción ${ }^{35}$.

$\mathrm{Al}$ ordenar la prohibición de discriminaciones arbitrarias el constituyente consagró dicha veda bajo la forma de su opuesto. Al impedir la arbitrariedad en la discriminación está consagrando a contrario sensu la procedencia de la discriminación, siempre que no sea arbitraria (principio de discriminación no arbitraria), estructurándose el principio de igualdad sobre dos líneas gruesas: la primera, consagradora de la igualdad en la ley (inciso primero) cuyo sujeto activo y pasivo son todas las personas, donde cualquier actuación en contraposición a la generalidad y objetividad de la ley produce una vulneración del principio igualitario (discriminación); y la segunda, que instituye la posibilidad del tratamiento diferenciado en el contenido de la ley bajo criterios racionales y objetivos por parte del legislador, y una aplicación por parte de la autoridad también diferenciada y sujeta a iguales parámetros de no arbitrariedad ${ }^{36}$.

\footnotetext{
${ }^{32}$ Cea Egaña, José Luis (2004): Derecho Constitucional Chileno. Tomo II (Santiago, Ediciones Universidad Católica), p. 130.

${ }^{33}$ Evans de la Cuadra, Enrique (1999): Los Derechos Constitucionales. Tomo II (Santiago, Editorial Jurídica), p. 125.

${ }^{34}$ Gómez Bernales, Gastón (2001): “El Principio de Igualdad Constitucional”, en Navarro Beltrán, Enrique (Ed.), 20 años de la Constitución chilena: 1981-2001 (ConoSur, Santiago), p. 177.

${ }^{35}$ Gómez Bernales (2001), pp. 179 y 181.

${ }^{36}$ JoRdÁn Díaz (2008), p. 181.
} 
De igual manera, cabe hacer concurrir lo dispuesto en el artículo 26 del Pacto Internacional de Derechos Civiles y Políticos que expresa:

"Todas las personas son iguales ante la ley y tienen derecho sin discriminación a igual protección de la ley. A este respecto, la ley prohibirá toda discriminación y garantizará a todas las personas protección igual y efectiva contra cualquier discriminación por motivos de raza, color, sexo, idioma, religión, opiniones politicas o de cualquier indole, origen nacional o social, posición económica, nacimiento o cualquier otra condición social".

Esta norma recoge las ideas abstractas señaladas y el contenido constitucional del principio de igualdad. Para el caso en comento, es importante la concurrencia de un requisito adicional para la igualdad en la ley: la prohibición inicial de establecer discriminaciones o diferenciaciones en razón de determinadas condiciones o categorías de personas, especialmente cabe precisar el "sexo", pues concurre directamente al caso en comento, pero también la "edad" es una condición de las personas que le son ajenas a su voluntad o decisión, concurriendo, a nuestro juicio, dentro de las condiciones adscritas a las personas y, por ende, prohibidas por el Pacto.

El tratado expresa una regla primaria y una secundaria. La primaria es la prohibición de discriminación en razón de tales condiciones. Pero, como las diferenciaciones están permitidas por regla general, la regla secundaria con relación a esas condiciones es que procede la diferenciación o discriminaciones en consideración a tales condiciones, pero con una exigencia mayor de justificación al legislador al disponerlas. Hay un imperativo prohibitivo de discriminar, pero si ésta se realiza, la justificación que debe dar el legislador es más exigente. Es lo que en la doctrina comparada se denomina juicio de legitimidad (por ejemplo, en el Derecho español ${ }^{37}$ ). En él, el Tribunal Constitucional debe examinar las razones justificantes de la diferenciación, determinando si ella es procedente o, por el contrario, la considera vulneradora del principio de igualdad. Tal juicio no es homogéneo, ya que respecto de aquellas condiciones que expresamente se prohíbe discriminar (el sexo, por ejemplo), la desigualación en razón de tales condiciones será aceptada únicamente bajo un canon más estricto y riguroso de justificación.

El Excmo. Tribunal Constitucional ha señalado en dos sentencias referidas a la inaplicabilidad por inconstitucional del art. 38 ter (Sentencias $N^{\circ}$ s. 1272 y 1348) que el principio de igualdad exige un trato igual para las personas que se encuentran en posiciones equivalentes y una tratativa desigual para aquellas que están en

\footnotetext{
${ }^{37}$ Sentencia del Tribunal Constitucional español $N^{\circ}$ 200/2001, c.j. $4^{\circ}$. Para un examen doctrinal del juicio de legitimidad en el caso español, ver: JoRdán Díaz (2008), pp. 99-106.
} 
posición diferente. Expresa que el principio de igualdad tiene dos dimensiones: 1) la igualdad ante la ley, y 2) la prohibición a la ley y a la autoridad de instituir diferencias arbitrarias. El Tribunal ha recogido su propia doctrina y de la Corte Suprema para definir el principio de igualdad. Expresa el Tribunal:

"La igualdad ante la ley consiste en que las normas jurídicas deben ser iguales para todas las personas que se encuentren en las mismas circunstancias y, consecuencialmente, diversas para aquellas que se encuentren en situaciones diferentes"38.

De igual manera, y siguiendo la doctrina y jurisprudencia alemana, la magistratura constitucional chilena sitúa como elemento clave el término de comparación (tertium comparationis) con relación al concepto "igualdades esenciales". Expresa el Tribunal que se considera vulnerada la igualdad "cuando un grupo de destinatarios de la norma, comparados con otro grupo de destinatarios de la norma, son tratados de manera distinta, a pesar de que entre ambos grupos no media ninguna diferencia de tal entidad o importancia que pudiera justificar un tratamiento desigual"39.

En el mismo sentido, el Tribunal ha indicado que la igualdad consagrada en el $19 \mathrm{~N}^{\circ} 2$ se extiende al art. $19 \mathrm{~N}^{\circ} 9$ con relación a la obligación del Estado de proteger "el libre e igualitario acceso a las acciones de promoción, protección y recuperación de la salud y de rehabilitación del individuo", haciendo aplicables los criterios esbozados en el $19 \mathrm{~N}^{\circ} 2$ al $19 \mathrm{~N}^{\circ} 9^{40}$.

\subsection{El examen abstracto de constitucionalidad entre el principio de igualdad y el art. 38 ter}

Ahora bien, cabe realizar el control de constitucionalidad del art. 38 TER. La norma dispone que para calcular el precio del afiliado, la ISAPRE aplicará al precio base los factores que correspondan de acuerdo a la tabla de factores. La Superintendencia de Salud está facultada para dictar las normas de general aplicación para determinar la estructura de la tabla de factores, "estableciendo tipos de beneficiarios, según sexo y condición de cotizante o carga, y los rangos de edad que se deban utilizar. Cada rango de edad que fije la Superintendencia en las instrucciones señaladas en el inciso precedente se sujetará a las siguientes reglas (...) En el marco de lo señalado en el inciso precedente, las Instituciones de Salud Previsional serán libres para determinar los factores de cada tabla que empleen".

${ }^{38}$ Sentencia $\mathrm{N}^{\circ} 1273$, considerando jurídico 55 y Sentencia $N^{\circ} 1348$ c.j. $41^{\circ}$.

${ }^{39}$ STC N ${ }^{\circ} 1273$, considerando jurídico 60 y STC Nº 1348, considerando jurídico 46.

${ }^{40}$ STC N ${ }^{\circ} 1273$, considerando jurídico 64 y STC Nº 1348, considerando jurídico 51. 
Necesariamente, para apreciar el art. 38 ter debemos remitirnos al art. $2^{\circ}$ letra n) de la Ley $\mathrm{N}^{\circ} 18.933$, que señala qué se entiende por tabla de factores para la ley. Éste expresa que esta es "aquella tabla elaborada por la Institución de Salud Previsional cuyos factores muestran la relación de precios del plan de salud para cada grupo de personas, según, edad, sexo y condición de cotizante o carga, con respecto a un grupo de referencia definido por la Superintendencia, en instrucciones de general aplicación, el cual asumirá el valor unitario".

De lo anterior podemos considerar: a) que para calcular el precio de un plan de salud se debe tener en consideración una tabla de factores; b) que dicha tabla de factores, definida legalmente, considera determinados "factores" que muestran la relación de precios para determinados grupos de personas; c) que el precio para cada grupo de persona considerará la edad (rango de edades expresamente señalados en el art. 38 ter), sexo y condición de cotizante o carga con respecto a un grupo de referencia definido por la Superintendencia de Salud.

El problema constitucional radica en cómo y de qué manera el legislador dispuso la conformación de la tabla de factores con relación al sexo y la edad.

Independiente que las personas reclamantes fuesen mujeres (que luego se considerará), podemos afirmar que la ley establece una tabla de factores en razón de sexo y edad. Se dispuso un criterio de diferenciación para la determinación del precio de los planes de salud entre los afiliados al sistema privado según si éstos son hombres o mujeres, o en consideración al grupo etáreo al que pertenecen.

Al existir una habilitación legal para diferenciar por sexo y edad, debemos examinar la calidad jurídica de esa diferenciación, si ella importa una discriminación arbitraria o no. La ley es la que permite diferenciar según estas condiciones de las personas, por lo que es necesario establecer si esa permisión legal es ajustada a la Constitución en consideración al principio de igualdad.

Como señalamos, y fundados en el art. $19 \mathrm{~N}^{\circ} 2$ y el art. 26 del Pacto de Derechos Civiles y Políticos, la diferenciación está permitida, siempre que ella no sea arbitraria, es decir, que esté justificada, y en el caso de ciertas condiciones (sexo y edad) la justificación debe someterse a un examen más riguroso y exigente. Lo que debe observarse en el examen es: a) si existe diferenciación y de qué tipo; b) si está justificada, y c) si esta justificación cumple con un estándar más alto de argumentación justificante. En el caso contrario, estaremos en presencia de una diferencia arbitraria y, por ende, inconstitucional.

Cabe tener presente los argumentos de las ISAPRES en torno al principio de igualdad. En la Sentencia Rol No 1273 , la ISAPRE requerida señaló que la justificación de las tablas de factores por sexo y edad no era arbitraria, pues: a) se incorporaron a los contratos de salud por motivos razonables, ya que el precio del 
plan sufre "variaciones en el tiempo para permitir que se mantenga el equilibrio económico que hace posible el funcionamiento de las ISAPRE y, por ende, del sistema en su conjunto"; b) que la diferenciación guarda relación con "la naturaleza, tanto jurídica como económica, de la cobertura" que esas instituciones de salud previsional entregan y, al mismo tiempo, constituiría un "mecanismo que permite objetivizar y pre-determinar las variaciones que sufrirán en el tiempo dichos precios, lo que, por cierto, opera a favor de los afiliados"; c) que la inclusión de las tablas busca dar plena igualdad entre las personas, siendo el sexo y la edad factores que afectan de manera objetiva y real el riesgo de salud de una persona y que, por ello, tales factores la ponen en una situación distinta de otros individuos.

En la Sentencia Rol No 1.348 la ISAPRE vinculada a la causa señaló que la tabla de factores no resultaría contraria a la Constitución, en cuanto: 1) que la incorporación de las tablas de factores de riesgo por sexo y edad en los contratos de salud para el cálculo de su precio obedece a razones técnicas que han sido evaluadas por el legislador y además su aplicación también ha sido regulada de manera estricta por la misma ley; 2 ) no se infringe en este caso la igualdad ante la ley, asegurada constitucionalmente en el numeral $2^{\circ}$ del artículo 19 de la Constitución Política, porque además de lo ya señalado es dable concordar en que las personas que celebran los contratos de salud se hallan en situaciones objetivas distintas según sea su edad y sexo. En otros términos, a juicio de la ISAPRE, la norma impugnada es garantía de esquemas objetivos, conocidos y técnicamente justificados de operación y actúa en el sentido de resguardar la igualdad e impedir la discriminación arbitraria que es la prohibida por el constituyente.

En síntesis, las razones de las ISAPRES que justifican la diferenciación (en los casos en concreto produciendo un alza en los planes de determinadas mujeres) son: 1) razones económicas de funcionamiento del sistema ISAPRE que requiere diferenciar según los riesgos asociados a sexo y edad para solventar el sistema; 2) un criterio de objetivación y predeterminación de las variaciones en el tiempo de los precios; 3) que los factores de riesgo sexo y edad fueron evaluados por el legislador (no indicándose cómo ni cuándo); 4) la objetividad de los factores de riesgo, pues las mujeres se encuentran en situación objetiva distinta a los hombres.

Que las razones esgrimidas no cumplen con el parámetro mínimo justificante, bajo un examen riguroso y exigente de diferenciación legal, pues, se fijan criterios extra constitucionales y no de derechos fundamentales para su procedencia, como lo es el criterio económico para el funcionamiento del sistema ISAPRE. El razonamiento esgrimido y referido a que sin la diferenciación en razón de sexo y edad no subsiste el sistema, no es un argumento constitucional, ya que no puede aceptarse desde la perspectiva de derechos fundamentales que un derecho sea 
vulnerado o violado para la subsistencia de un área regulada privada, sino que el criterio es al revés, el mercado regulado debe subsistir bajo la premisa de respeto irrestricto a los derechos fundamentales. Una idea contraria sería excluir a la persona como centro medular del ordenamiento constitucional chileno.

Que el sexo y la edad son condiciones objetivas es un argumento aparentemente correcto, pero sustancialmente engañoso, ya que afirmar que el sexo y la edad son factores objetivos no es ni constitucional ni inconstitucional de por sí, sino lo que es relevante desde la perspectiva constitucional, y que se debe acreditar, es si la justificación de la incorporación de esos factores es objetiva y razonable bajo criterios generalmente aceptados, y si cumplen con un nivel mayor de exigencia. La objetividad se vincula a que la diferenciación debe ser desinteresada, es decir, ajena a intereses particulares. La razonabilidad, a juicio del Tribunal y siguiendo a Linares Quintana "(...) es el cartabón o standard de acuerdo con el cual debe apreciarse la medida de la igualdad o de la desigualdad", agregando que "Lo razonable es lo opuesto a lo arbitrario" y que "el acto irrazonable o arbitrario es defectuoso y es inconstitucional" 41 . Se debe tener claro que, y bajo un razonamiento inverso, no será objetiva ni razonable la diferenciación si esta es artificiosa o injustificada.

Se ha esgrimido que la supuesta objetividad está dada por ser las mujeres más riesgosas que los hombres a determinada edad, por lo que si tratamos de objetivizar el argumento, deberíamos afirmar que la justificación de la desigualación es el "riesgo", por ser mayor la probabilidad de contraer enfermedades o de estar en una condición de salud que requiere más atención médica (por ejemplo, el embarazo), utilizando más el sistema privado y con ello haciendo subir los costos de funcionamiento del sistema. Por tanto, la norma que establece la tabla de factores, y que permite que tales factores sean el sexo y la edad, se justifica en razón del riesgo asociado a determinados grupos de personas. La afirmación de lo anterior es que al ser determinados grupos de personas más riesgosos, se pueden establecer diferencias que permitan el alza de los planes de salud de éstas.

El problema es que la ley asocia el riesgo a "grupos de personas" según el art. 20 letra n) y no a personas determinadas que efectivamente sean riesgosas. Es decir, la justificación de la diferenciación por "riesgo" se le aplica a una categoría de personas según su sexo y edad, incluyendo en ella a determinadas personas que deben soportar un plan más caro, independiente si ellas se encuentran o no en la situación riesgosa objetiva (que sean efectivamente más caras para el sistema privado), por lo que la ley establece una "presunción de derecho del riesgo" para

${ }^{41}$ Sentencia Rol No 1348 , considerandos jurídicos 43 y 44; Sentencia Rol N 1273 , considerandos jurídicos 57 y 58. 
determinados grupos de personas, que no sabemos de antemano quiénes son, sino que la regulación infra-legal y contractual determinarán.

El problema acá es abstracto y pone en colisión directa los arts. 20 letra $\mathrm{n}$ ) y 38 ter con el art. $19 \mathrm{~N}^{\circ} 2$ de la Constitución. Independiente si el grupo de riesgo sean hombres o mujeres, jóvenes o personas de edad avanzada, el conflicto constitucional de las dos normas es que califica el riesgo de las personas en razón de su pertenencia a un "grupo de personas", conjunto determinado por sexo y edad, y no por el riesgo propiamente tal de los sujetos. La ley realiza un análisis de generalización, encuadrando en la calidad de riesgosas a personas muy diferentes entre sí, en términos sanitarios (por ejemplo, personas más enfermizas que otras, personas que utilizan en mayor medida el sistema privado con las que no), conformando un determinado "grupo" únicamente por su sexo y edad, ubicando en tal grupo a personas sanitariamente riesgosas y personas que no son riesgosas o de menor riesgo, otorgándole a las personas no riesgosas o de menor riesgo la calidad jurídica de riesgosas sin serlo, instituyéndose de esa manera una discriminación injustificada en perjuicio de tales personas, pues deben soportar las alzas de planes y un trato de persona riesgosa cuando no se pertenece, necesariamente, a esa categoría.

Es posible discutir si el riesgo es en sí mismo es una justificación relevante, pero estimamos que lo que no es procedente desde la perspectiva constitucional es que la ley disponga que por el hecho de pertenecer a un grupo de personas en razón de sexo y edad, se le atribuya en abstracto y a priori, una calidad de riesgosa en términos sanitarios cuando no concurre esa calificación, lo que conlleva en concreto que, independiente si esa persona es en términos reales y objetivos riesgosa, su plan de salud será más elevado sólo por tener determinado sexo y edad.

Las ISAPRES, al fijar los grupos de personas por sexo y edad, siempre tendrán que incorporar a ellos personas de mayor riesgo con las que no lo son, de modo que nos encontramos ante un problema constitucional que no permite darle una significación distinta y que permita su constitucionalidad. La ley obliga a las ISAPRES a categorizar, calificación que, utilizando el término de comparación, resultará siempre discriminatoria, pues existirán personas que son tratadas de una determinada manera, cuando deben ser tratadas de manera diferente. Al utilizar la situación factual de las personas riesgosas como término de comparación con las personas no riesgosas o de menor riesgo, podemos concluir que las personas que encuadradas en esta última figura están en una situación diferente y se les trata de igual manera que las personas riesgosas, instituyéndose una discriminación arbitraria en su perjuicio. ¿Cuál es la justificación para que la ley trate de igual manera a personas que se sitúan en posiciones factuales distintas?, estimamos que la ley no otorga razones suficientes para dicho trato discriminatorio. 
Por otro lado, el texto legal cuestionado pone en situación de discriminación, utilizando el término de comparación, con relación a otros grupos de sexo y edad. Así, puede que a un grupo de un determinado sexo y edad (grupo X) se les califique de mayor riesgo que a un grupo etario equivalente y de distinto sexo, o de un grupo del mismo sexo pero de un tramo de edad diferente (grupo Y) (cuestión que ocurre en la realidad). El problema radica en que dentro del grupo etario $\mathrm{Y}$ pueden concurrir personas que sean sanitariamente más riesgosas que muchos miembros del grupo $\mathrm{X}$, calificado de mayor riesgo, debiendo pagar los miembros de grupo $\mathrm{X}$ un plan más caro, aunque dentro de sus miembros existan personas de menor riesgo que en el grupo $Y$, simplemente por haber sido calificados como riesgosos según su sexo y edad.

Si el fundamento de la distinción está en el riesgo, los miembros del grupo X menos riesgosos no sólo deberían pagar menos con relación a los otros miembros de $\mathrm{X}$ más riesgosos, sino también menos con relación a los miembros del grupo $\mathrm{Y}$ que son más riesgosos que ellos. Al efectuar la comparación entre grupos, la calificación riesgosa para personas que no lo son acarrea una discriminación.

Para ser más claros, un grupo de personas, por ejemplo, mujeres de 60 o más años (para conciliar el argumento con los requerimientos de inaplicabilidad), tiene un plan de salud más caro que las mujeres que no están en esa edad y que los hombres de igual o menor edad. Cualquier sea la comparación, nos dará una discriminación dentro del grupo como fuera del grupo calificado como de mayor riesgo.

Si comparamos la situación dentro del grupo, habrá mujeres que son más riesgosas que otras, pero todas, por el solo hecho de ser sexo femenino y estar en determinado tramo de edad, son calificadas como de mayor riesgo y, por ende, deben pagar un plan de salud más caro. La pregunta es ¿por qué todas las mujeres de tales edades deben pagar lo mismo?, ¿Por qué una mujer que goza de buena salud acreditada debe pagar lo mismo que una persona de su mismo sexo con una salud más frágil?; ello, en el entendido que el alza de salud sea en razón del riesgo, pues hay diferencia de riesgo entre estas mujeres. No hay razón justificada para ello en razón del riesgo.

Siguiendo con los ejemplos, ¿por qué el grupo de mujeres de 60 años o más debe pagar más que las mujeres de 59 años o menos?, no existe razón de riesgo acreditada que nos permita afirmar que "todas" las mujeres a partir de determinada edad son más riesgosas que las mujeres de uno o más años menores. Bajo la lógica expresada en las letras anteriores, habrán mujeres de 60 o más años "más y menos riesgosas" comparadas con las mujeres menores de 60 años, pero independiente del riesgo real y efectivo, deberán pagar más por su plan de salud. Lo lógico sería 
que las mujeres de 60 o más años, y las mujeres menores de 60 años paguen una plan de salud vinculado al riesgo real y no bajo un riesgo presunto, de manera que no todas las mujeres de 60 o más años deberían pagar más caro que las mujeres menores de 60 , porque comparativamente, en razón del riesgo, están en situaciones diferentes, asunto que las ubica en una situación de discriminación.

Otro ejemplo, y en la misma línea del anterior, si realizamos una comparación entre grupos de hombres y de mujeres de distintas edades también concurre la discriminación. Si un grupo de mujeres (de 60 o más años) se les califica de mayor riesgo, se debe efectuar una comparación con los hombres de igual tramo de edad. Lo que puede ocurrir, y ocurre, es que el grupo de mujeres tiene un plan de salud más caro, independiente del riesgo real en comparación con el grupo de hombres, ya que por el hecho de ser mujer de determinada edad se le califica como riesgosa, basado en un modelo teórico del riesgo, no en una comparación objetiva de los grupos. Es más, puede pasar que al interior del grupo de mujeres existan mujeres menos riesgosas sanitariamente que algunos miembros del grupo de hombres de igual tramo etario, por lo que tales mujeres deberían tener un plan de salud más barato que los hombres más riesgosos, pero ello no ocurre así, situando en una situación comparada de discriminación a esas mujeres de menor riesgo en comparación con los hombres del grupo etario equivalente.

En otro orden de cosas, debe precisarse que la seguridad social comprende un conjunto de programas que tienen por objeto proteger el ingreso de los trabajadores frente al desempleo, a las enfermedades, a los accidentes, a la incapacidad laboral durante la vejez; a sus dependientes frente a la invalidez o muerte del jefe de hogar y, finalmente, a mejorar los niveles de consumo de los menores y mayores en situación de pobreza e indigencia.

Por ser un derecho reconocido en la Constitución Política encuentra como destinatarios a todos los ciudadanos y ciudadanas sin distinción de edad, sexo o condición social. Lo anterior busca garantizar una protección real y eficaz ante la vejez, la muerte, la discapacidad, las enfermedades o accidentes, la maternidad, el desempleo y todas las contingencias sociales que crean estados de necesidad.

Cuando los prestadores de seguridad social establecen diferencias de carácter arbitrarias, tales como las permitidas por la norma jurídica impugnada en el presente proceso; vulneran la esencia de aquélla al generar precisamente uno de los efectos que la seguridad social desea remediar, a saber, la disminución sustantiva de los ingresos de las personas en función de la ocurrencia de contingencias, en este caso, de salud.

Por otra parte, la protección de la función reproductora de la mujer está íntimamente ligada a la promoción de la igualdad de género. Por ello, las prestaciones 
del seguro de maternidad constituyen una pieza determinante para permitir a las mujeres y a sus familias mantener su nivel de vida cuando la madre no puede trabajar. En este caso, igualdad de género significa no sólo trato igualitario para hombres y mujeres en situaciones iguales o similares, sino también medidas para garantizar la igualdad de hecho para las mujeres.

Finalmente, hay que analizar las Actas de la Comisión de Estudios de la Nueva Constitución. En ellas puede constatarse que el constituyente sostuvo que debía tenerse cuidado en la redacción de la norma constitucional respectiva, por cuanto debía "[...] tenerse cuidado en la disposición que se apruebe, porque [...] en esta parte es donde más interesa el principio de la igualdad ante la ley, el cual se violaría al dejar entregado al arbitrio de los particulares la organización de diversos sistemas previsionales, ya que éstos aumentarían en grado superlativo”. En el seno del mismo organismo, el Comisionado señor Guzmán advirtió "[...] que precisamente el alcance de la palabra "uniforme" impediría el establecimiento de discriminaciones" ${ }^{42}$.

En conclusión, desde la perspectiva del principio de igualdad, no encontramos una razón justificada en la ley ni en los argumentos esgrimidos por las ISAPRE para diferencias por grupos de persona según su sexo y edad, concurriendo una discriminación arbitraria. El riesgo como argumento es discriminador, por cuanto la ley obliga a la ISAPRE a calificar a las personas en grupos por sexo y edad, conllevando la existencia de personas calificadas como de mayor riesgo sin serlo al efectuar una comparación con otras personas de igual sexo y distinta edad, o de distinto sexo y de edades equivalentes o diferentes. Si la razón para diferenciar es el riesgo, los arts. 179 y 199 vulneran el principio de igualdad, porque es un riesgo general por sexo y edad, y no un riesgo real y efectivo según la persona, independiente de su sexo y edad.

\section{LA VULNERACIÓN DEL DERECHO DE LIBRE ELECCIÓN DEL SISTEMA DE SALUD}

Dentro de los argumentos sustantivos que deben ser abordados en esta problemática debe analizarse, especialmente, el ámbito protegido por la Constitución Política y el contenido esencial del derecho a la libre elección del sistema de salud, por un lado, en relación a la libertad de iniciativa en materia económica, por el otro. Este apartado examina los argumentos de constitucionalidad del artículo 38 ter impugnado desde el punto de vista del derecho de libre elección del sistema de

${ }^{42}$ Comisión de estudio de la nueva Constitución Política de la República (1978): Actas Oficiales (Sesión $393^{\mathrm{a}}$; 4 de julio de 1978). 
salud -en sus dos dimensiones: subjetiva y objetiva- y en relación a la presunta vulneración de la libre iniciativa en materia económica.

La Constitución establece, en su artículo 19, número 9, que: “[...] Es deber preferente del Estado garantizar la ejecución de las acciones de salud, sea que se presten a través de instituciones públicas o privadas, en la forma y condiciones que determine la ley, la que podrá establecer cotizaciones obligatorias. Cada persona tendrá el derecho a elegir el sistema de salud al que desee acogerse, sea éste estatal o privado". A su vez, el constituyente originario estimó de tal importancia la protección de este derecho de libre elección que decidió dispensar la tutela iusfundamental que brinda el recurso de protección en el artículo 20 de la Constitución, no así garantizando el derecho general de acceso a las prestaciones de salud.

Que el derecho de libre elección tiene una dimensión individual y una institucional u objetiva. En primer lugar, analizaremos la dimensión individual del derecho.

\subsection{Dimensión individual del derecho de libre elección del sistema de salud}

En su faz individual, el derecho de libre elección asegura una esfera de autonomía a todas las personas para optar entre el sistema público de salud y el privado. Como ha señalado la doctrina nacional más autorizada. Se trata, por lo tanto, de un derecho de autonomía o de corte negativo, cuyo objeto de protección iusfundamental es impedir que cualquier agente -estatal o particular-interfiera ilegal o arbitrariamente con la facultad subjetiva de elección. Tal imperativo se colige no sólo de la obligación de protección y promoción de los derechos fundamentales -establecida en el artículo $5^{\circ}$ de la Constitución-, sino también en el principio de vinculación directa de la Carta Fundamental y de su fuerza normativa -consagrada en el artículo $6^{\circ}$ de la misma-.

\subsection{Aplicación del derecho de libre elección entre particulares}

Como bien ha señalado el Excmo. Tribunal Constitucional en su reciente jurisprudencia -y aplicando uno de los desarrollos contemporáneos más avanzados de la teoría general de los derechos fundamentales-, los derechos fundamentales tienen un radio de vigencia de aplicación en las relaciones entre particulares. Esta alta magistratura ya señaló, en su fallo Rol No 976 de 2008, que "el deber de los particulares de respetar y promover los derechos inherentes a la dignidad de la persona persiste, inalterado, en las relaciones convencionales entre privados, cualquiera sea su naturaleza. Sostener lo contrario implicaría admitir la posibilidad de que, invocando la autonomía de la voluntad, tales derechos y, a su vez, la dignidad de 
la persona, pudieran ser menoscabados o lesionados en su esencia, interpretación que, a la luz de lo ya explicado, se torna constitucionalmente insostenible"43.

En efecto, en respaldo de tal argumentación, el Tribunal cita vasta doctrina que desarrolla el alcance y la modulación a partir de la cual los derechos fundamentales son extendidos, en su protección, al ámbito de las relaciones inter privatos. Esta posición, además, se alinea con los desarrollos modernos de la teoría de los derechos fundamentales, tanto en el ámbito europeo continental, como en el ámbito estadounidense ${ }^{44}$. En sistemas constitucionales con órganos de control de constitucionalidad, éstos verifican que el orden objetivo de valores que programa la Constitución -entre los cuales se contempla de la dignidad humana y el derecho de libre elección del sistema de salud- no se vea alterado o menoscabado en las normas contractuales que emanan de la libertad negocial. En otros términos, pesa en los órganos del Estado una obligación de velar por el cumplimiento y tutela de estos derechos recogidos en la Carta Fundamental y que irradian a todo el ordenamiento jurídico infraconstitucional, incluyendo, por cierto, las reglas del derecho privado ${ }^{45}$.

La doctrina, nacional y comparada, está conteste en aceptar que los preceptos legales deben ajustarse en su forma y fondo a las normas constitucionales. Es más, la interpretación de los mismos requiere conciliar los márgenes de la autonomía de la voluntad con la protección de otros bienes y valores de carácter constitucional. Es por esta razón que en el examen de afectación del derecho de libre elección del sistema de salud debe ser considerado el Derecho público, cuyas normas son de corte imperativo y cuya base se encuentra en los preceptos constitucionales y en las normas recogidas en tratados internacionales que establecen derechos fundamentales. En otros términos, las cláusulas generales del derecho privado requieren ser moduladas y ajustadas a los valores establecidos en la Constitución Política, puesto que sirven de puntos de irrupción de los derechos fundamentales en las normas legales aplicables al tráfico privado.

En este sentido, debe tenerse presente que, el principio de libertad contractual, recogido en el artículo 1545 del Código Civil -con base constitucional en diversas normas que aseguran la autonomía negocial de los individuos-, debe ser

\footnotetext{
${ }^{43}$ Sentencia Rol No 976, considerando jurídico 40.

${ }^{44}$ Contreras, Pablo (2009): Poder Privado y Derechos. Eficacia Horizontal y Ponderación de los Derechos Fundamentales (Santiago, Ediciones Universidad Alberto Hurtado).

${ }^{45}$ Para la aplicación de los Derechos Fundamentales entre privados, ver: Jordán Díaz, Tomás: "Algunos Comentarios a la Sentencia del Tribunal Constitucional N 976/2008”, en Revista Domos, Facultad de Derecho de la Universidad de Viña del Mar, 2009.
} 
armonizado en su ejercicio con los límites que surgen de la misma Constitución. Tal conclusión es obligada, incluso si uno atiende a las mismas reglas del citado cuerpo legal, ya que el artículo 1462 señala que hay objeto ilícito en todo pacto que contraviene el Derecho público chileno, donde se encuentran, por cierto, las normas constitucionales sobre derechos fundamentales y los valores que sirven de bases de la institucionalidad. Por lo tanto, y como bien lo ha expresado un autor español, la libertad contractual protegida por la Constitución no alcanza la vulneración o anulación de otros derechos establecidos en la misma ${ }^{46}$. En términos simples, la autonomía de la voluntad constitucionalmente garantizada no es absoluta, sino que encuentra como límites los derechos esenciales que emanan de la naturaleza humana.

Que tal aplicación de la teoría del efecto de irradiación de los derechos fundamentales y su eficacia en el ámbito de las relaciones entre particulares es plenamente aplicable al derecho de libre elección del sistema de salud contemplado en nuestra Constitución. Pues, tal como nuestro Tribunal ha consignado, "es, para estos efectos, la base constitucional y de orden público de todo contrato de salud, con plena vigencia en el contexto de dicha convención, razón por la cual ésta no puede incluir cláusulas que desconozcan o aminoren tales derechos. Consiguientemente, estipulaciones de esa índole devendrían en inválidas por ser contrarias a la Constitución, efecto que tendría contemplar estipulaciones que, directamente o no, signifiquen que la contraparte quede, de facto, impedida de ejercer la plenitud de todos y cada uno de los atributos que le han sido asegurados en esa disposición suprema" (cons. $43^{\circ}$ ). Este considerando no hace más que confirmar y aplicar la eficacia del derecho de libre elección del sistema de salud como uno de los límites constitucionales y legales que tiene la autonomía contractual de las ISAPRE en la determinación del contenido de los planes de salud.

\subsection{Contenido esencial del derecho de libre elección}

Sin embargo, para que la conclusión anterior sea admisible, el Tribunal debe acreditar el efecto de privación absoluta de los atributos que comprende la faz individual del derecho de libre elección o, en otras palabras, la afectación del contenido esencial del derecho.

El artículo 19, número 26 de la Constitución prescribe que se asegura a todas las personas la "seguridad de que [sic] los preceptos legales que por mandato de la Constitución regulen o complementen las garantías que ésta establece o que

\footnotetext{
${ }^{46}$ NARANJO DE LA CRUZ, Rafael (2002): Los límites de los derechos fundamentales en las relaciones entre particulares (Madrid, Centro de Estudios Políticos y Constitucionales).
} 
las limiten en los casos en que ella lo autoriza, no podrán afectar los derechos en su esencia, ni imponer condiciones, tributos o requisitos que impidan su libre ejercicio". Este numeral, cuyos orígenes se remontan al artículo 19 de la Ley Fundamental de Bonn alemana y el artículo 53 de la Constitución española de $1978^{47}$, consagra una institución conocida como la garantía del contenido esencial de los derechos fundamentales, elemento nuclear en la teoría de los límites a los mismos.

Para verificar si es procedente la afectación del contenido esencial del derecho de libre elección, debe primero determinarse su sentido y alcance como labor básica de hermenéutica.

Para ello, debe atenderse a un precedente de nuestra magistratura que temprana y acertadamente delimitó lo que se entiende por contenido esencial del derecho. En efecto, en la sentencia del Tribunal Constitucional Rol No 43, de 24 de febrero de 1987, se afirma que:

"La esencia del derecho debemos conceptuarla desde el punto de vista del ordenamiento positivo y dentro de este ámbito precisar el alcance de la norma constitucional en los términos más sencillos, para que sea entendido por todos y no sólo por los estudiosos de la ciencia jurídica. Desde esta perspectiva, debemos entender que un derecho es afectado en su 'esencia' cuando se le priva de aquello que le es consustancial, de manera tal que deja de ser reconocible, y que se impide el 'libre ejercicio' en aquellos casos en que el legislador lo somete a exigencias que lo hacen irrealizable, lo entraban más allá de lo razonable o lo privan de tutela jurídica" (considerando 21 ${ }^{\circ}$, énfasis agregado).

Efectivamente, este leading case ha prefigurado la discusión nacional en concordancia con el debate europeo ${ }^{48}$. En este sentido, el contenido esencial de los derechos constituye un límite absoluto, una última barrera de protección del derecho frente a su regulación legal, fijando un contenido resistente a toda restricción del legislador y no relativizable ${ }^{49}$. En otros términos, se busca proteger y resguardar

\footnotetext{
${ }^{47}$ Véase, por todos, a Verdugo, Mario; Pfeffer, Emilio y Nogueira, Humberto (2002): Derecho Constitucional (Santiago, Editorial Jurídica de Chile, 2a ed.), p. 327.

${ }^{48}$ Véase a Gavara de Cara, Juan Carlos (1994): Derechos Fundamentales y Desarrollo Legislativo. La Garantía del Contenido Esencial de los Derechos Fundamentales en la Ley Fundamental de Bonn (Madrid, Centro de Estudios Constitucionales); Prieto Sanchís, Luis (2003): Justicia Constitucional y Derechos Fundamentales (Madrid, Trotta), pp. 230-237; BRAGe (2004), pp. 232-239 y 396-409. Para el caso chileno, se puede revisar a Nogueira (2006): Lineamientos de Interpretación Constitucional y del Bloque Constitucional de Derechos (Santiago, Editorial Librotecnia), pp. 331-334 y Aldunate (2008): Derechos Fundamentales (Santiago, LegalPublishing), pp. 261-264.

${ }^{49}$ BRAGE (2004), pp. 234-235.
} 
una esfera de autonomía, la cual no sea impedida en su "libre ejercicio" y que sea "reconocida en cuanto tal".

En el caso de marras, es menester analizar si el artículo 38 ter en examen afecta el contenido esencial del derecho consagrado y garantizado por el artículo 19, número 9, en relación al numeral 26, ambos de la Constitución Política.

Para que se produzca una afectación del contenido esencial se requiere que el derecho sea privado o restringido severamente en las facultades de ejercicio, haciéndolo irreconocible o impidiendo efectuar las conductas amparadas por el mismo.

En el caso en cuestión, el afiliado a la ISAPRE, en virtud de la tabla y en razón de los factores que ella establece, se ve impedido de elegir libremente el sistema de salud de su preferencia. El derecho de libre elección le corresponde al beneficiario, titular individual del derecho. Se trata de una de sus facultades esenciales puesto que, si es privada de la misma, ya no se reconoce derecho alguno de elección del sistema de salud, por un lado, y el titular carece de potestad subjetiva alguna reconocida en la Constitución Política, por el otro. Esta afectación del contenido esencial se da, precisamente, por la amplitud extrema e incondicionada que faculta el artículo 38 ter en examen, habilitando que las ISAPRES, a través de factores discriminatorios y de forma unilateral, eleven los costos de los planes actuales de determinados beneficiarios sin constatar, en los hechos, que exista un aumento real del riesgo por enfermedad, como ya hemos explicado. Esta conducta, amparada en un precepto legal vaciado del contenido mínimo que exige la reserva legal, termina por anular y suprimir toda posibilidad que tiene el usuario de elegir entre los sistemas de salud, obligándolo a retirarse de las ISAPRES y forzándolo a someterse al sistema público de salud que, como analizaremos a continuación, no puede negarse a brindarle cobertura y acceso a las acciones de salud. Por lo tanto, la norma impugnada tiene como consecuencia directa un ejercicio sobredimensionado de la libertad negocial de las ISAPRE, vulnerando el contenido esencial del derecho de libre elección de los beneficiarios que se encuentran afectados por los factores estipulados en la Tabla de Factores de Riesgo.

\subsection{Sobre la libre iniciativa en materia económica}

Por otra parte, la severa afectación del contenido esencial del derecho de libre elección no tiene ningún parangón con la presunta violación del derecho de libre iniciativa en materia económica, consagrado en el artículo 19, número 21 de la Constitución Política. Los alegatos expuestos por quienes representan los intereses de las ISAPRES dibujan un escenario fatalista en virtud del cual, la libre iniciativa 
económica y la autonomía de estas empresas quedaría completamente disminuido hasta desaparecer por completo.

Adicionalmente, se trata de una de las clásicas críticas a la eficacia de los derechos fundamentales entre particulares, la cual sostiene que esta vigencia horizontal de los derechos sacrificaría en extremo la libertad contractual y la facultad de autodirigir los negocios de los privados. Según sostienen estos autores, la publificación del derecho privado traería como natural consecuencia la eliminación completa y absoluta de la autonomía negocial y del principio de libertad contractual que constituye la regla de clausura de esta esfera del Derecho.

Tal argumentación debe ser necesariamente desechada, toda vez que la limitación de la libre iniciativa en materia económica no sólo se encuentra autorizada por la Carta Fundamental, sino que también es necesaria para la correcta articulación y armonización de todos los derechos, principios y valores que se encuentran recogidos en la Constitución Política. Se trata de un ejercicio de concordancia práctica de los preceptos iusfundamentales, en el marco de una hermenéutica sistemática y finalista del texto constitucional.

Bajo el marco enunciado, la Constitución no asegura un derecho de libertad económica absoluto e irrestricto; por el contrario, permite que se establezcan límites con el objeto de optimizar todos los bienes y derechos constitucionales. Esta es la razón de por qué el mismo artículo 19, número 21 de la Constitución establece cláusulas limitativas para el derecho en comento. Pero, adicionalmente, una norma legal no puede autorizar nunca un ejercicio tal de la libertad económica que conlleve la supresión total de los atributos esenciales de otro derecho, como es el caso de la libre elección del sistema de salud. En este orden de ideas, la reserva de ley -garantía básica de derechos fundamentales en un Estado democrático- requiere dar certezas del ámbito protegido de la libre iniciativa en materia económica, por un lado, pero además debe permitir que ésta sea articulada con otros derechos, como el consagrado en el artículo 19, número 9 de la Constitución.

En otros términos, una correcta regulación de la libertad de empresa y de la autonomía negocial de las ISAPRE permitiría optimizar tanto este derecho como la libre elección del sistema de salud. Empero, el sistema actual establecido en el artículo 38 ter en examen, es tan deficitario que permite la anulación total de un derecho y no la optimización de ambos, mediante limitaciones válidas de cara al ordenamiento constitucional. En otras palabras, bastaría que el legislador señalase con precisión cuáles son los límites legítimos de la libre iniciativa en materia económica en relación a los contratos de salud para permitir no sólo este derecho, sino también el ejercicio del derecho de acceso a la salud que garantiza la Constitución para el beneficiario. La eliminación de la tabla de factores no im- 
portaría, en ningún caso, una eliminación total de las facultades que el derecho establecido en el artículo 19, número 21 establece, sino que importaría aplicar límites a la posibilidad de decisiones unilaterales por parte de estas empresas. A diferencia del efecto inconstitucional y altamente desproporcionado que se produce respecto del derecho de libre elección de los beneficiarios -siendo afectado en su esencia-, las ISAPRES mantendrían diversas facultades de la libre iniciativa en materia económica para dirigir y mantener sus negocios y, en ningún caso, habría una limitación de tal magnitud que prive absolutamente la posibilidad de brindar acceso a acciones privadas de salud.

En consecuencia, la declaración de inconstitucionalidad del precepto legal impugnado no sólo no afecta la libertad de empresa de la que son titulares las ISAPRE, sino que, adicionalmente, permite concretar y armonizar, de mejor forma, un sano equilibrio entre los derechos que se encuentran en tensión con el actual sistema.

\subsection{Dimensión institucional del derecho de libre elección}

Que la conclusión anteriormente arribada debe complementarse debidamente con una mirada sistemática y finalista de la Carta Fundamental, incorporando todos los principios y valores que esta misma contempla.

En dicha línea, debe tenerse presente que los derechos fundamentales no sólo importan aspectos subjetivos e individuales sino que, además, al ser considerados como un orden objetivo de valores, generan consecuencias institucionales en todo el ordenamiento jurídico. Se trata, en consecuencia, de la conocida dimensión objetiva de los derechos fundamentales, cuestión que ha sido reconocida por vuestra magistratura, como se explica a continuación.

La dimensión objetiva de los derechos es un aspecto de los mismos que comprende las implicancias sociales e institucionales del contenido mismo del derecho, tanto en la aplicación de las normas infraconstitucionales, como en el diseño de las instituciones y de las prácticas de los órganos del Estado. Como señala la doctrina española, "[e]l contenido objetivo persigue la garantía de la dimensión objetiva del derecho fundamental, en cuanto norma principal. Ese contenido objetivo no es sino el mandato de optimización de la libertad individual (o colectiva) protegida en cada concreto derecho fundamental mediante un permiso o una prohibición. Dicho mandato posee una doble faz. De un lado impone a todo aquel que ejerza poder público el deber positivo de proteger los derechos fundamentales que puedan verse afectados en aquella situación en la que haga uso de dicho poder. De otro lado, le impone el deber de abstenerse 
de todo acto contrario al derecho fundamental en cuestión" 50 . Por lo tanto, este contenido importa una obligación positiva para los poderes públicos y los órganos del Estado, en orden a promover y resguardar los derechos establecidos en la Constitución Política. Es, además, una concreción del mandato que la misma Carta Fundamental establece en su artículo $5^{\circ}$, respecto de todos los derechos esenciales que emanan de la naturaleza humana y la correcta interpretación de la voz "asegura", verbo rector en el inciso que inaugura el artículo 19 que recoge y consagra los derechos constitucionales.

Tal desarrollo dogmático y jurisprudencial del Derecho comparado, no es ajeno a la evolución actual de nuestro constitucionalismo. En efecto, y basándose en una correcta interpretación sobre el objeto de los derechos fundamentales, nuestro Tribunal ha señalado, en la Sentencia Rol Nº 740 de 2007 que:

"los derechos fundamentales - que se aseguran a todas las personas-poseen una doble naturaleza que justifica su rol central en las Cartas Fundamentales y en los instrumentos internacionales de derechos humanos. Por un lado, constituyen facultades que se reconocen a su titular, dando lugar a su dimensión 'subjetiva', mientras que, por otro, dan unidad y sentido a todo el ordenamiento jurídico, lo que se conoce como su dimensión 'objetiva'. De allí que todo conflicto constitucional que, como el de la especie, tienda a constatar la eventual vulneración de derechos fundamentales tiene una especial significación que no puede dejar indiferente a ningún operador del derecho" (cons. $47^{\circ}$, énfasis agregado) ${ }^{51}$.

Por lo tanto, y tal como lo constata el sentenciador, ya no se trata "sólo de poder invalidar todo acto en infracción del deber de no ejercer poder público en el ámbito protegido por el derecho fundamental, sino, y esto es capital, de dar amparo constitucional a cualquiera de los posibles comportamientos que en principio se puedan encuadrar en la definición abstracta de la esfera vital que es objeto del permiso constitucional establecido por la norma iusfundamental" 52 .

Que, tal como se ha demostrado más arriba, el artículo 38 ter en examen permite un ejercicio sin limitaciones de la autonomía de la voluntad de las ISAPRES y ello repercute, con tal intensidad, que termina privando de los atributos básicos y consustanciales del derecho de libre elección del sistema de

\footnotetext{
${ }^{50}$ BASTIDA, Francisco et al. (2004): Teoría General de los Derechos Fundamentales en la Constitución Española de 1978 (Madrid, Tecnos), pp. 108-109.

${ }^{51}$ Sobre la dimensión objetiva de los derechos fundamentales con relación a la inaplicabilidad en concreto del art. 38 TER, ver: JORDÁN DÍAZ (2008).

52 BASTIDA (2004), p. 110.
} 
salud. La faz individual del derecho queda anulada, pero sus efectos no repercuten, únicamente, frente a los titulares individuales y concretos del derecho, sino que, por el contrario, repercute gravemente en todo el sistema de salud, en su conjunto.

Tal conclusión es obligada cuando uno observa los efectos globales de la aplicación de la tabla de factores de riesgo para la determinación de las alzas de los planes de cobertura de las ISAPRES. Como es evidente, aquellos cotizantes que, en virtud de factores flagrantemente discriminatorios, se ven en una situación obligada de retirarse del sistema privado de salud, no tienen ninguna otra alternativa que dirigirse al sistema público de FONASA. Sin embargo, estos usuarios llegan al sistema público sin haber cotizado en él y, no obstante, el sistema público está obligado no sólo a aceptarlos sino que, también, a asumir los costos que potencialmente pudieren originar sin haber percibido fondo alguno de la cotización que ha hecho durante su vida la persona. En otros términos, se trata de un precepto legal que habilita a las ISAPRE a mantener los usuarios y cotizantes a su elección y faculta que cuando sus costos pudieren aumentarse, sea el sistema público el que se encargue de estas personas y asuma su costo, pero habiendo percibido durante un buen tiempo las cotizaciones del usuario. Por lo tanto, el vaciamiento de la reserva de ley no sólo perjudica el ejercicio individual del derecho a la protección de la salud, consagrado en el artículo 19, número 9 de la Constitución Política, sino también estructura y posibilita una manipulación de la elección del sistema y de cuál deben afrontar, en definitiva, aquellos usuarios que (potencialmente) pudieren presentar mayores costos. Con ello, las ISAPRES tendrían una extensión tan desmedida de su libertad contractual que, en último término, pueden decidir -sin ninguna limitación de por medio- cuáles son los usuarios del sistema público y cuáles son los del sistema privado, invirtiendo los ejes nucleares del sistema de salud ideado por los redactores de la Constitución de 1980.

En conclusión, permitir tales grados de afectación del contenido esencial del derecho de libre elección no afectará únicamente a titulares individuales y concretos de aquel derecho, sino que, en términos agregados y abstractos, afecta a numerosos titulares que en potencia pueden verse afectados $y$, finalmente y en términos sistémicos, viola el esquema que la misma Constitución ha previsto para que se efectúen las acciones de salud a través de un sistema público y uno privado y donde la decisión de elección recae en las personas naturales. En consecuencia, el precepto legal habilita irrestrictamente a las ISAPRE a guardar todas las llaves del sistema, determinar las elecciones de los particulares, distribuir costos de acciones de saludo y, finalmente, beneficiarse económicamente del mismo. 


\section{BiBLIOGRAFÍA}

Aldunate (2008): Derechos Fundamentales (Santiago, LegalPublishing).

Alexy, Robert (1993): Teoría de los Derechos Fundamentales (Centro de Estudios Políticos y Constitucionales, Madrid).

BASTIDA, Francisco et al. (2004): Teoría General de los Derechos Fundamentales en la Constitución Española de 1978 (Madrid, Tecnos).

Bobbio, Norberto (1996): Teoría general del derecho (Debate, Madrid, Cuarta Reimpresión).

Brage Camazano, Joaquín (2004): Los limites a los derechos fundamentales (Madrid, Dykinson).

BurT, Robert (2000): Constitución y Conflicto (Eudeba, Departamento de Publicaciones de la Facultad de Derecho de la Universidad de Buenos Aires, Primera Edición).

Calvo García, Manuel (ed.) (1995): Interpretación y argumentación jurídica. Trabajos del Seminario de Metodología Jurídica Vol. I (Prensas Universitarias de Zaragoza, Primera Edición).

Carmona Santander, Carlos (1998-1999): “Tendencias del Tribunal Constitucional en la Relación Ley-Reglamento", en Revista de Derecho Público (Volumen 61, 1998/1999).

Cea Egaña, José Luis (2004): Derecho Constitucional Chileno. Tomo II (Santiago, Ediciones Universidad Católica).

Comisión de estudio de la nueva Constitución Política de la República (1978): Actas Oficiales (Sesión 403a, 18 de julio de 1978).

Contreras, Pablo (2009): Poder Privado y Derechos. Eficacia Horizontal y Ponderación de los Derechos Fundamentales (Santiago, Ediciones Universidad Alberto Hurtado).

Díez-Picazo, Luis María (2005): Sistema de derechos fundamentales (Thomson, Civitas, Segunda Edición, Madrid).

García Pino, Gonzalo (2004): La Reserva Legal de Derechos Constitucionales: ¿Poder Legislativo contra la Administración? (Santiago, Colección de Investigaciones Jurídicas, $\mathrm{N}^{\circ}$ 5, Universidad Alberto Hurtado).

Evans de la Cuadra, Enrique (1999): Los Derechos Constitucionales. Tomo II (Santiago, Editorial Jurídica).

Fernández GonzÁlez, Miguel Ángel (2001): Principio Constitucional de Igualdad ante la Ley (Editorial ConoSur, Santiago).

GAVARA DE CARA, Juan Carlos (2005): Contenido y función del término de comparación en la aplicación del principio de igualdad (Thomson Aranzadi, Navarra). 
Gavara de Cara, Juan Carlos (2004): "El Principio de Igualdad", en Gavara DE Cara, Juan Carlos (Ed.), Constitución, Desarrollo, Rasgos de Identidad y Valorización en el XXV Aniversario (1978-2003) (Institut de Ciences Polítiques i Socials, J. M. Bosch Editor, Barcelona, España).

Gavara de Cara, Juan Carlos (1994): Derechos Fundamentales y Desarrollo Legislativo. La Garantía del Contenido Esencial de los Derechos Fundamentales en la Ley Fundamental de Bonn (Madrid, Centro de Estudios Constitucionales).

Gómez Bernales, Gastón (2001): "El Principio de Igualdad Constitucional”, en Navarro Beltrán, Enrique (Ed.), 20 años de la Constitución chilena: 19812001 (ConoSur, Santiago).

Jordán Díaz, Tomás (2008): La Protección de los Derechos Sociales: Modelos Comparados de Tutela Jurisprudencial (España y Chile) (Santiago, Colección de Investigaciones Jurídicas, $\mathrm{N}^{\circ}$ 10, Universidad Alberto Hurtado 2006, publicada el 2008).

Jordán Díaz, Tomás: "Algunos Comentarios a la Sentencia del Tribunal Constitucional N 976/2008”, en Revista Domos, Facultad de Derecho de la Universidad de Viña del Mar, 2009.

Ministerio Secretaría General de la Presidencia (2010): Doctrina Constitucional del Presidente Ricardo Lagos Escobar (2000-2006). Tomo I (Santiago, Gobierno de Chile, Editorial LOM).

NARANJo DE LA CRUZ, Rafael (2002): Los límites de los derechos fundamentales en las relaciones entre particulares (Madrid, Centro de Estudios Políticos y Constitucionales).

Nogueira (2006): Lineamientos de Interpretación Constitucional y del Bloque Constitucional de Derechos (Santiago, Editorial Librotecnia).

Nogueira AlCALÁ, Humberto (1997): “El Derecho a la Igualdad en la Jurisprudencia Constitucional”, en Revista de Derecho de la Universidad Católica de Valparaíso (Vol. XVIII, Actas de las XXVII Jornadas de Derecho Público).

Peces-Barba, Gregorio (1999): Curso de Derechos Fundamentales, Teoria General (Universidad Carlos III de Madrid, Boletín Oficial del Estado, Madrid).

Pérez Luño, Antonio E. (2005): Dimensiones de la Igualdad (Instituto de Derechos Humanos Bartolomé de las Casas, Universidad Carlos III de Madrid, Fundación el Monte, Cuadernos "Bartolomé de las Casas" No 34).

Pérez Royo, Javier (2003): Curso de Derecho Constitucional (Marcial Pons, Madrid, 2003).

Prieto Sanchís, Luis (2003): Justicia Constitucional y Derechos Fundamentales (Madrid, Trotta). 
Prieto Sanchís, Luis (1997): Constitucionalismo y positivismo (Fontamara, México).

SuAy Rincón, José (1985): El principio de Igualdad en la Justicia Constitucional (Instituto de Estudio de Administración Local, Madrid).

Verdugo, Mario; Pfeffer, Emilio y Nogueira, Humberto (2002): Derecho Constitucional (Santiago, Editorial Jurídica de Chile, 2a ed.).

Zapata Larraín, Patricio (2008): Justicia Constitucional. Teoría y Práctica en el Derecho Chileno y Comparado (Editorial Jurídica de Chile, Santiago).

ZúNiga URbina, Francisco: "Ley y reglamento en la jurisprudencia del Tribunal Constitucional (del afrancesamiento a la germanización)" (ponencia no publicada). 